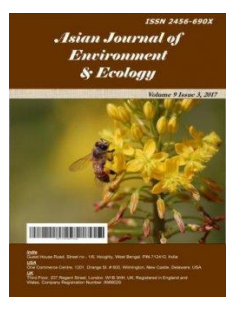

\title{
The Full Hierarchical Structuration of Species Abundances Reliably Inferred from the Numerical Extrapolation of Still Partial Samplings: A Case Study with Marine Snail Communities in Mannar Gulf (India)
}

\author{
Jean Béguinot ${ }^{1^{*}}$ \\ ${ }^{1}$ Department of Biogéosciences, Université Bourgogne Franche-Comté, UMR 6282, CNRS, 6, \\ Boulevard Gabriel, 21000 Dijon, France.
}

Author's contribution

The sole author designed, analyzed, interpreted and prepared the manuscript.

Article Information

DOI: $10.9734 / A J E E / 2018 / 43918$

Editor(s):

(1) Dr. Adamczyk Bartosz, Department of Food and Environmental Sciences, University of Helsinki, Finland.

Reviewers:

(1) Manoel Fernando Demétrio, Universidade Federal da Grande Dourados, Brazil.

(2) Tiogué Tekounegning Claudine, The University of Dschang, Cameroon. (3) Yayan Mardiansyah Assuyuti, Syarif Hidayatullah State Islamic University, Indonesia. Complete Peer review History: http://www.sciencedomain.org/review-history/26313

Original Research Article

Received 29 June 2018

Accepted 15 September 2018

Published 21 September 2018

\begin{abstract}
The detailed analysis of Species Abundance Distributions ("S.A.D.s") can shed light on how member-species organize themselves within communities, provided that the complete distribution of species abundances is made available first. In this perspective, the numerical extrapolation applied to incomplete "S.A.D." can effectively compensate for S.A.D.s incompleteness, when having to deal with substantially incomplete samplings. Indeed, almost as much information can be released from extrapolated "S.A.D.s" as would be obtained from truly complete "S.A.D.s", although the taxonomic identities of unrecorded species remain of course ignored by numerical extrapolation.

To take full advantage of this new approach, a recently developed procedure allowing the leastbiased numerical extrapolation of "S.A.D.s" has been applied to three partially sampled gastropods communities associated to coral-reef in Mannar Gulf (S-E India).

The following main results were derived from the three numerically completed "S.A.D.s": (i) once
\end{abstract}

${ }^{*}$ Corresponding author: E-mail: jean-beguinot@orange.fr; 
completed, all three numerically "S.A.D.s" fairly well comply with the log-normal model, suggesting that, in all three communities, the process of hierarchical structuration of species abundances likely involves the combined contributions of many independent factors; (ii) moreover, the same holds true for each of the two coexisting feeding guilds (primary and secondary consumers) considered separately; (iii) when compared to secondary consumers, the guild of primary consumers has a much lower species richness but, on the other hand, exhibits a more strongly structured distribution of species abundances, which materializes not only in term of the apparent unevenness of species abundances but also after having disentangled the genuine intensity of the underlying process driving the hierarchical structuration.

All the preceding features are shared in common by the three communities studied, in line with the similarity of their environmental contexts. Only minor features can actually slightly distinguish between communities, reflecting the difference in distances between them.

Keywords: Coral reef; gastropod; incomplete inventory; ranked abundance distribution; species diversity; evenness; climate change; global warming.

\section{INTRODUCTION}

Tropical marine ecosystems in shallow waters are of major concerns to ecologists and conservationists, as they are considered as one of the first ecosystem to suffer significantly from obvious impacts due to the on-going climatewarming [1,2]. Moreover, these same ecosystems are of major interest, being considered as embodying remarkably high levels of diversity and biological complexity [1,3-5]. However, precisely because of their usually high species richness, also including numerous rare species, the samplings of these communities often remain substantially incomplete [6]. More generally, sampling incompleteness is doomed to become the unavoidable consequence of the generalization of "rapid assessments" and "quick surveys", at least when having to deal with species-rich communities, as is usually the case with terrestrial or marine invertebrates faunas, especially under tropical climate. In turn, such partial inventories prevent a reliable appreciation of the key descriptive and functional aspects of the internal organization within species communities [7-9]. Hence, the recently acknowledged necessity to implement relevant numerical extrapolations applied to both: (i) the as-recorded species accumulation process, beyond the already reached sampling-size and (ii) the as-recorded distribution of species abundances in the studied community.

Indeed, the extrapolated numerical data, regarding all the species that had remained undetected after partial sampling, is absolutely necessary to gain access to the aforementioned descriptive and functional features of the internal organization within species communities.

In particular, once properly numerically completed (and only when it is so: [6]), the distribution of species abundances can provide synthetic data, both qualitative and quantitative, about the underlying process that drives the hierarchical structuring of species abundances within community [10-14]. Although no deeper details may be extracted from this synthetic overview, it has, yet, the advantage of being straightforward. In particular, this synthetic approach does not involve the long and tedious analytical programs that would be otherwise required to go deeper in the details of the structuring processes. As such, this synthetic approach can serve, at least, as a convenient preliminary investigation.

As complete - or numerically completed abundance distributions are mandatory for this purpose, new procedures for the numerical extrapolation of (i) the Species Accumulation Curve and (ii) the Species Abundance Distribution have recently been developed, aiming at providing reliable, least-biased inferences about (i) the number and (ii) the distribution of abundances of all those species that remained undetected after incomplete samplings.

Hereafter, I report and discuss the results derived from the numerical extrapolations applied to the partial inventories of three marine Gastropod communities associated to tropical coral reefs surrounding three small islands within Mannar Gulf Biosphere Reserve (south-eastern coast of India). Partial samplings were carried out by Mohanraj and co-workers [15], while the estimates of the true (total) species richness of each of these three communities were already reported by Béguinot [16].

In turn, based on the results derived from these numerical extrapolations, I address the following questions: 
i) Which kind of process is involved in the hierarchical structuring of species abundances, according to the type of models that fit best to completed Species Abundance Distributions;

ii) To what extent the intensity of the hierarchical structuring of species abundances actually differs from the resulting apparent degree of abundances unevenness in each case?

iii) Are there significant difference between gastropod feeding guilds, as regards the hierarchical structuring process (in term of structuring intensity) and the resulting pattern of species abundances (in term of apparent degree of unevenness);

iv) Does any significant difference exist between the three Gastropods communities, as regards the mode and intensity of species abundance structuration and, if any, does these differences can be related to inter-sites distances?

Relevantly addressing all these issues systematically require to consider complete Species Abundance Distributions; hence the necessity to numerically extrapolate them with minimized bias, making use of the recently developed procedures for this purpose.

\section{MATERIALS AND METHODS}

\subsection{Field Data}

The coral reefs surrounding the shores of three small islands, located in "Mannar Gulf Biosphere Reserve" (islands of 'Hare', 'Vaan' and 'Koswari') were sampled for their associated gastropods communities. The recorded data, issued from these partial surveys (on which numerical extrapolations will be based) is reported in details in Mohanraj et al. [15] and the reader is invited to browse this publication for the contextual information regarding the sites and the implemented sampling methods. The number $\mathrm{N}_{0}$ of collected individuals and the number $R_{0}$ of recorded species are recalled here at Table 1, for each investigated site. At all three sites, the numbers $f_{1}$ of singletons (species recorded only once) are closed to $20 \%$ of the total number $R_{0}$ of recorded species, which denotes substantial incompleteness for each of the three samplings, a common situation in practice, as already underlined. As all the species lists reported by the authors include the respective abundances of the recorded species, the corresponding data was appropriate to implement the procedure of numerical extrapolation.

\subsection{The Numerical Extrapolation Procedure and Its Exploitation}

As mentioned above, the Species Abundance Distributions ("S.A.D.") provides the basic data necessary (i) to describe the pattern of structuration of species within community and (ii) to qualify and quantify the underlying process that drives this structuration.

Yet, to accurately exploit its full potential $[17,18]$, the "S.A.D." requires:

- $\quad$ first, to be corrected for bias resulting from drawing stochasticity liable to the finite size of samplings,

- second, and still more importantly, to be completed by numerical extrapolation, to the extent that sampling is suspected to be incomplete, as revealed by the subsistence of singletons - as is the case here.

The appropriate procedure of correction and, subsequently, of least-biased numerical extrapolation of the as-recorded "S.A.D." is described in details in Béguinot [18] and briefly summarized in Appendix 1. In addition, an example of implementation of the procedure is commented in details in Béguinot [19].

Classically, the "S.A.D." is graphically presented according to the so-called "Ranked Abundance Distribution" (also known as "Whittaker plot"), according to which the (log-transformed) abundances $a_{i}$ are plotted against the rank $i$ of species, the species being ordered by decreasing values of abundance (with, thus, $a_{1}$ and $a_{\mathrm{St}}$ respectively standing for the highest and the lowest levels of species abundance in a community of $S_{t}$ species).

\subsubsection{Description of the pattern of species abundance structuration}

The "S.A.D." (completed by extrapolation to include undetected species, if any) conveys all the relevant quantitative data relative to the internal structuration of species abundances within community. In particular, it is always advisable to use species-abundance plots to study evenness or unevenness [20]. For commodity, the "S.A.D." may be synthetically reduced to its two major descriptors: The total species richness " $\mathrm{S}_{\mathrm{t}}$ " and the degree of 
unevenness " $U$ " of the abundance distribution. According to the aforementioned, classical mode of representation of "S.A.D.", it goes natural to quantify the degree of abundance unevenness $U$ as the average slope of the abundance decrease along the whole range of the abundance distribution, as already proposed [21], that is:

$U=\left[\log \left(a_{1}\right)-\log \left(a_{S t}\right)\right] /\left(S_{t}-1\right)$

$=\left[\log \left(a_{1} / a_{S t}\right)\right] /\left(S_{t}-1\right)$

\subsubsection{Qualification of the underlying} structuring process: type and intensity

Beyond the mere description of the pattern of structuration, quantified by $\mathrm{U}$, the complete "S.A.D." can help addressing several important questions regarding the intensity and the type of process driving the hierarchical structuration of abundances in the community (i.e. the differential allocations of relative abundances among member-species of the community).

As regards the type of structuring process involved, it is possible to distinguish between two major alternative hypotheses: Schematically, the hierarchical structuration of abundances may result either: (i) from the contribution of only one dominant factor or (ii) from the combined contributions of many mutually independent factors acting together. This may be tested by checking the conformity of the corresponding "S.A.D." to either the log-series model or the lognormal model, respectively [10,22-25].

Now, as regards the intensity of the structuring process, it is first necessary to remind that the degree of unevenness $U$ is inadequate in this respect, due to its additional mathematical dependence upon the species richness $S_{t}[26,27]$ (see also Appendix 3), which ultimately results in masking the genuine contribution of the structuring process itself $[12,13,28]$. To get rid of this spurious dependence, deprived from biological significance, it has been shown appropriate to cancel its influence by comparing the actual "S.A.D." to the corresponding "brokenstick" distribution [29], computed for the same species richness $S_{t}[19,30,31]$. Accordingly, the genuine intensity, "Istr", of the hierarchical structuring process is relevantly defined by standardizing the unevenness of the actual "S.A.D." to the unevenness of the corresponding "broken-stick" distribution, computed for the same species richness $S_{t}$, that is:

$$
I_{s t r}=U / U^{\prime}=\log \left(a_{1} / a_{S t}\right) / \log \left(a_{1}^{\prime} / a^{\prime}{ }_{S t}\right)
$$

with the abundances being classically logtransformed and with $\mathrm{a}_{1}$ and $\mathrm{a}_{\mathrm{St}}$ standing for the highest and the lowest abundances in the studied community and $a_{1}{ }_{1}$ and $a_{\text {'st }}$ standing for the highest and the lowest abundances in the corresponding "broken-stick" distribution.

Thus defined, freed from the purely mathematical influence of species richness, the index $I_{\text {str }}$ accounts for those biological factors only that indeed contribute to the hierarchical structuring of abundances within species community.

Note at last, that the methodologic approach above may be applied, as well, to any subsets of interest, for example to each of the feeding guilds that co-occur in the species community.

\section{RESULTS}

\subsection{Estimated Total Species Richness of Each Community}

The three communities have rather similar estimated total species richness: 'Koswari': 53 species, 'Vaan': 51 species, 'Hare' 49 species (Table 1, [16]).

Table 1. The number of collected individuals $N_{0}$, the number of recorded species $R_{0}$, the type of nonparametric estimator selected as being the least-biased, the estimated number $\Delta$ of unrecorded species, the resulting estimate of the "true" total species richness $S_{t}(=\operatorname{Ro}+\Delta)$, the resulting estimated level of sampling completeness $R_{0} / S_{t}$. Estimations are computed according to the least-biased procedure: Selection key provided in Appendix 2

\begin{tabular}{lccc}
\hline Parameters of sampling and numerical & \multicolumn{3}{c}{ Sites } \\
\cline { 2 - 4 } extrapolation & Hare & Vaan & Koswari \\
\hline nb. collected individuals $\mathrm{N}_{0}$ & 310 & 484 & 416 \\
nb. recorded species $\mathrm{R}_{0}$ & 35 & 40 & 38 \\
least-biased estimator selected & $\mathrm{JK}-5$ & $\mathrm{JK}-5$ & $\mathrm{JK}-4$ \\
nb. unrecorded species $\Delta$ & 14 & 11 & 15 \\
total species richness $\mathbf{S}_{\mathrm{t}}$ & $\mathbf{4 9}$ & $\mathbf{5 1}$ & $\mathbf{5 3}$ \\
sample completeness $\mathrm{R}_{0} / \mathrm{S}_{\mathrm{t}}$ & $\mathbf{7 1} \%$ & $\mathbf{7 8 \%}$ & $\mathbf{7 2 \%}$ \\
\hline
\end{tabular}


In this respect, the spatial distance between communities does not seem to have any influence: the (slight) difference of species richness is the same between 'Hare' (49 species) and 'Vaan' (51 species), separated by $>100 \mathrm{~km}$, than between 'Koswari' (53 species) and 'Vaan' (51 species), although distant by $3 \mathrm{~km}$ only.

A similar lack of singling out of 'Hare' community, as compared to 'Koswari' and 'Vaan' communities, is reported in an another study of reef-associated gastropod assemblages [32], considering the levels of (i) species diversity, (ii) species richness and (iii) evenness of species abundances.

\subsection{Species Abundance Distribution for Each Community, Duly Corrected and Extrapolated}

Figs. $1,2, \quad 3$, provide the graphical representations of the Species Abundance Distribution ("S.A.D.") for each of the three communities under study. These "S.A.D.s" have been (i) bias-corrected and then (ii) numerically extrapolated according to equations (A1.1) and (A1.2) respectively: see Appendix 1.

According to the usual convention of graphical representation for S.A.D.s,

- Along the abscissa, member-species are ranked by decreasing values of their respective abundances (relative abundance ' $a_{i}$ ' for the species of rank ' $i$ ');

- Along the ordinate, the relative abundances are plotted according to a logarithmic scale $\left(\log _{10}\right)$ (although, for specific purpose, an ordinary untransformed scale may be adopted, as suggested in [29]).

The (bias corrected) abundances of the recorded species are plotted as grey circles, while the extrapolated part of the abundance distribution is plotted as a thick solid line.

\subsection{Testing for the Type of Process Involved in the Structuring of Species Abundances}

Figs. 4-5, 8-9, 12-13 provide the comparisons of the "S.A.D." of each community to the corresponding "log-series" and "log-normal" models, computed for the same species richness respectively. As mentioned in Methods section, these comparisons allow to infer which kind of process is more likely to be involved in the hierarchical structuration of species abundances: schematically, the "log-series" model suggests that only one (or very few) dominant factor is structuring the distribution of species abundances in the community while the "lognormal" model suggests the intermingled contributions of numerous and mutually independent factors, involved together in the structuration of the community.

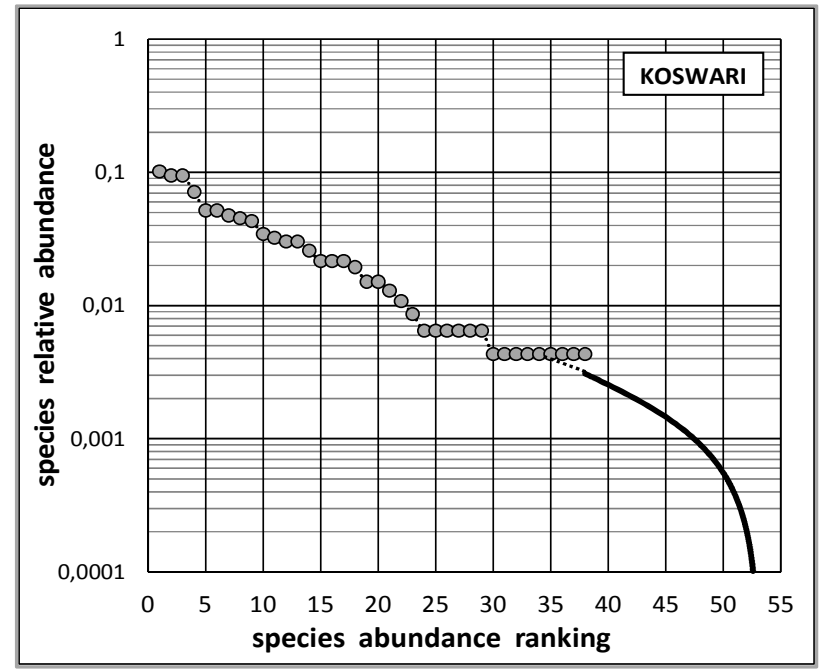

Fig. 1. The bias-corrected and extrapolated species abundance distribution ("S.A.D.") for the reef-associated gastropod community around 'Koswari' island: Grey circles: Recorded part of the "S.A.D." after correction for bias; solid line: least-biased extrapolation of the abundance distribution for the set of unrecorded species due to incomplete sampling

(Sampling completeness: $72 \%$ ) 


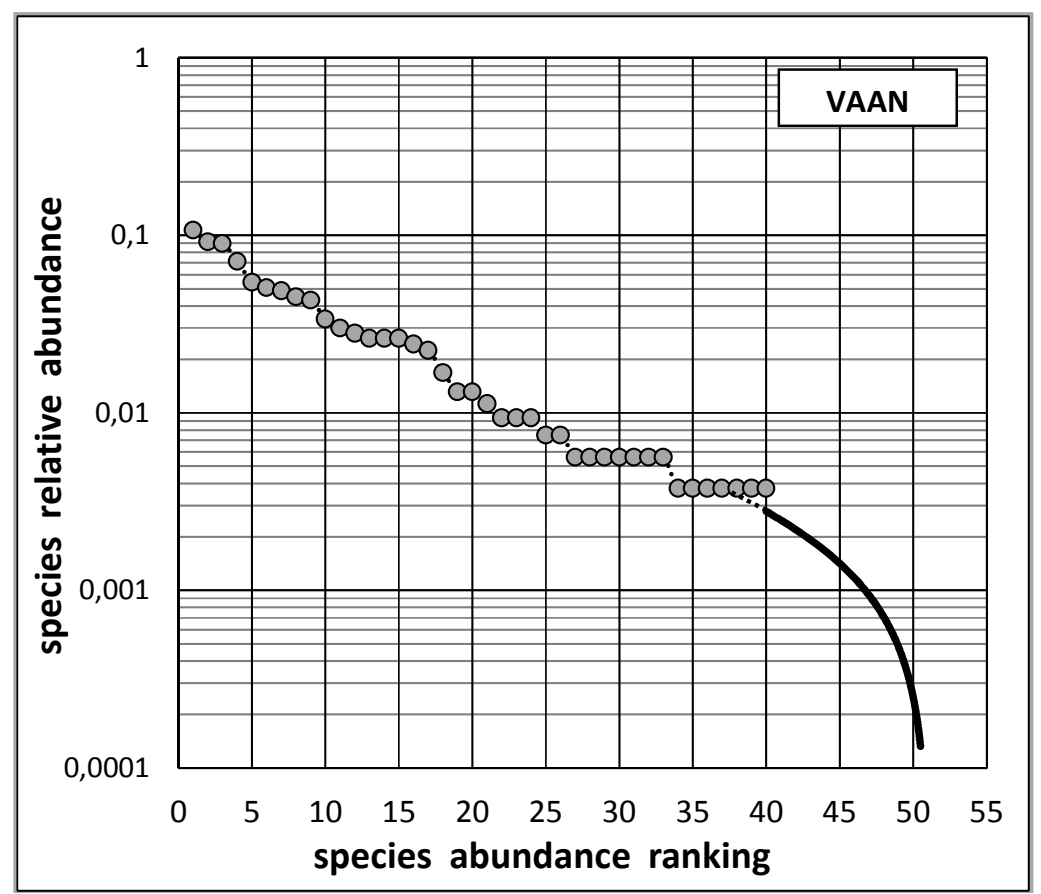

Fig. 2. The bias-corrected and extrapolated species abundance distribution ("S.A.D.") for the reef-associated gastropod community around 'Vaan' island: grey circles: recorded part of the S.A.D. after correction for bias; solid line: least-biased extrapolation for the set of unrecorded species due to incomplete sampling (sampling completeness: $78 \%$ )

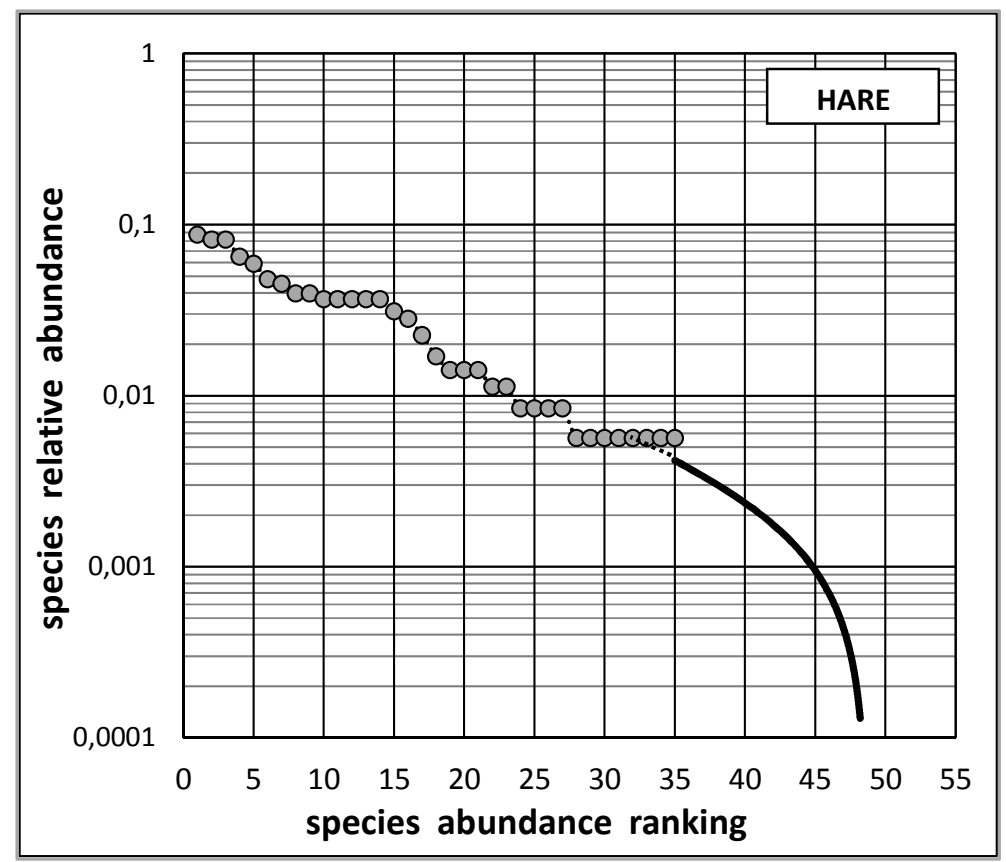

Fig. 3. The bias-corrected and extrapolated species abundance distribution ("S.A.D.") for the reef-associated gastropod community around 'Hare' island: grey circles: recorded part of the "S.A.D". After correction for bias; solid line: least-biased extrapolation for the set of unrecorded species due to incomplete sampling (sampling completeness: $71 \%$ ) 
For all three communities, the species abundance distributions clearly fit best the "lognormal" model than the "log-series" model.

Now, Figs. 6-7, 10-11, 14-15 allow a closer examination of the fitting to the "log-normal" model and, in particular, highlight in all three cases a local departure from the otherwise fairly well fitted "log-normal" model. Specifically, the most abundant species (species of rank $\mathrm{i}=1$ and, to a much lesser extent, of rank $i=2$ ) has an abundance level which is only about half the prediction by the "log-normal" model. In all three cases, the gap is statistically highly significant (statistical test based on the Bayesian inference of the probability distribution of values for the abundance $a_{1}$ of the species of rank $i=1: p<$ $0.001)$. The likely origin and ecological meaning of this gap is discussed later.
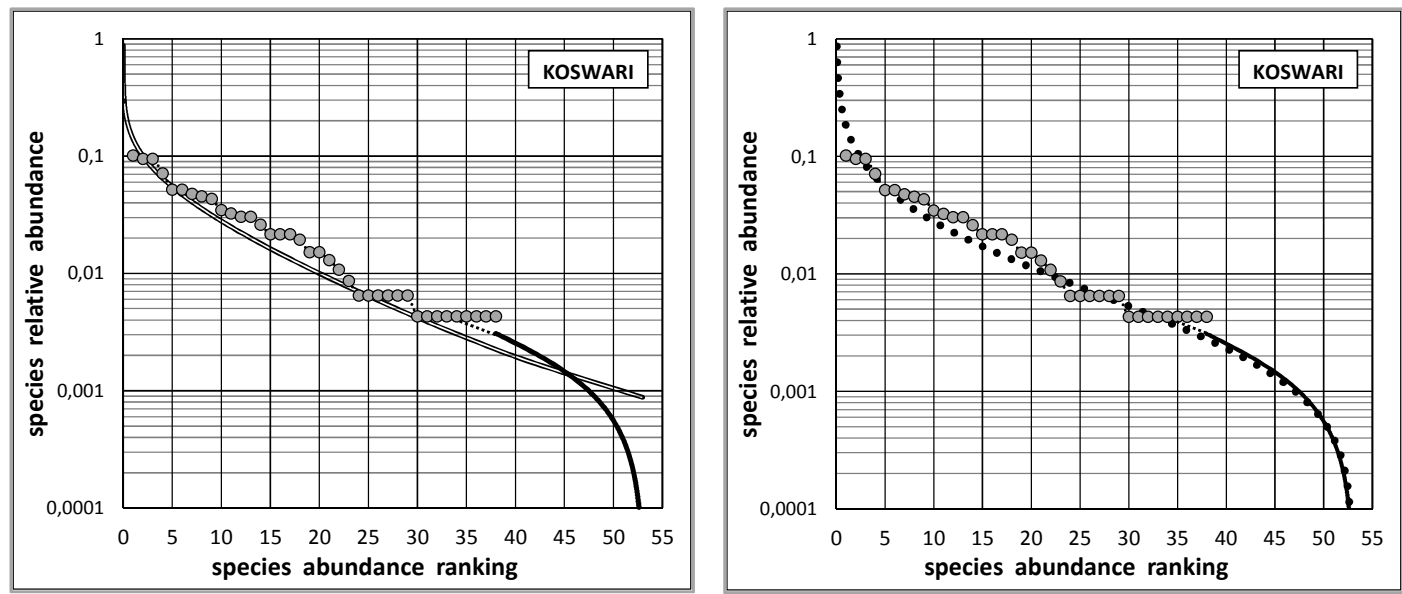

Fig. 4. Comparison between the bias-corrected and extrapolated "S.A.D." for the community at 'Koswari' island (grey circles and solid line) and the corresponding "log-series" model (Double line)

Fig. 5. Comparison between the bias-corrected and extrapolated "S.A.D." for the community at 'Koswari' island (grey circles and solid line) and the corresponding "log-normal" model (Dotted line)
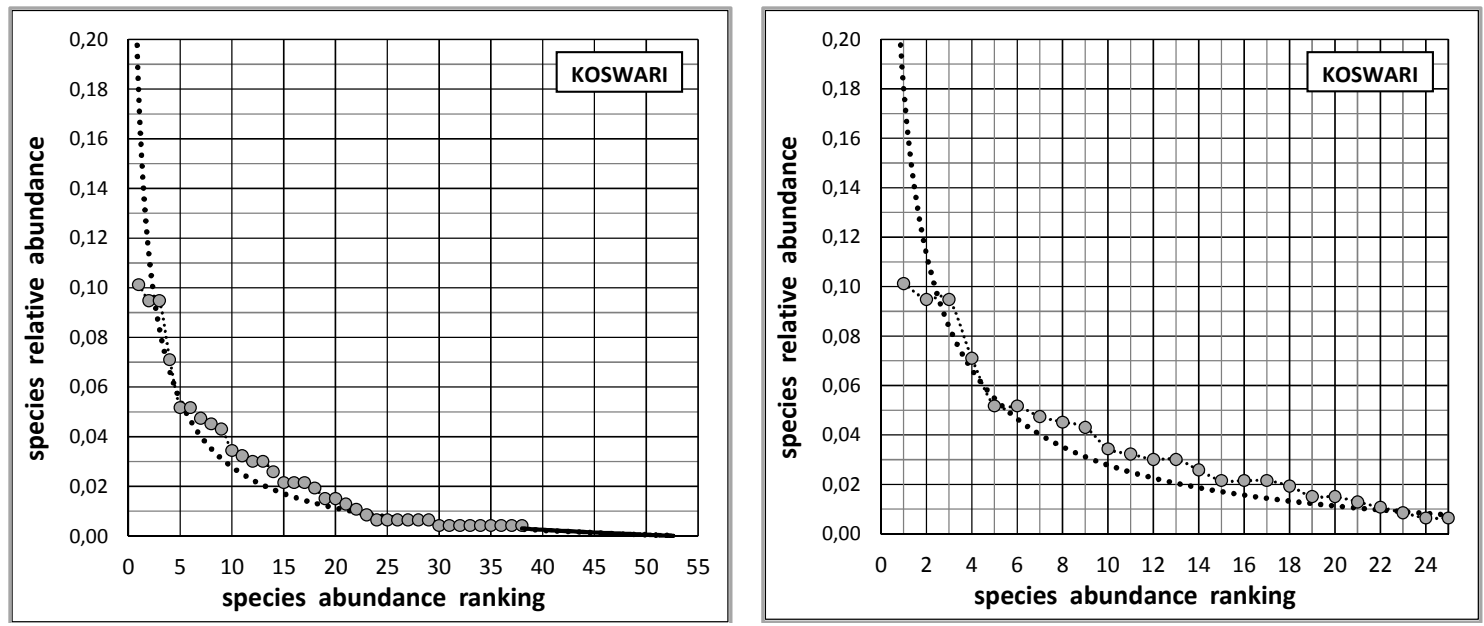

Fig. 6. Comparison between the bias-corrected and extrapolated "S.A.D." for the community at 'Koswari' island (grey circles and solid line) and the corresponding "log-normal” model (dotted line)

Fig. 7. Same as Fig. 6 with arithmetical scale for abundances (instead of the traditional logarithmic scale), which offers a more direct visual appreciation of relative abundances, as suggested by [29] 

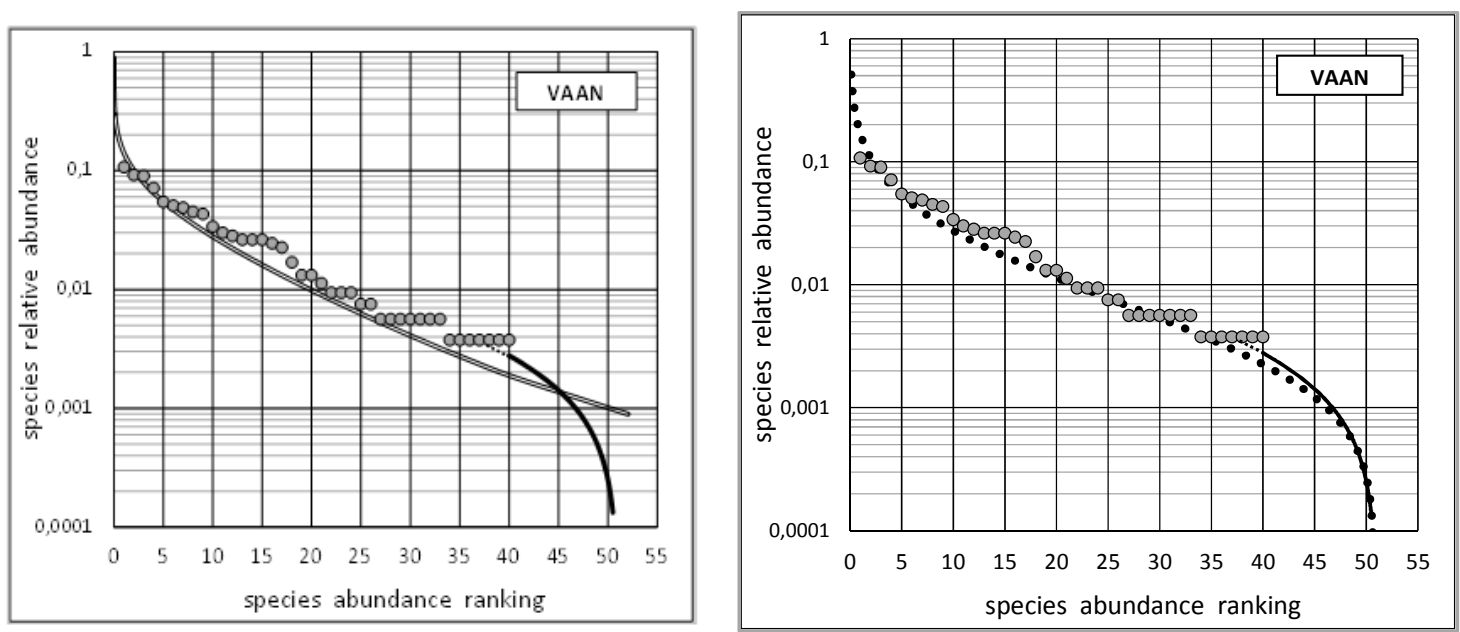

Fig. 8. Comparison between the bias-corrected and extrapolated "S.A.D." for the community at 'Vaan' island (grey circles and solid line) and the corresponding "log-series" model

(Double line)

Fig. 9. Comparison between the bias-corrected and extrapolated "S.A.D." for the community at 'Vaan' island (grey circles and solid line) and the corresponding "log-normal" model

(Dotted line)
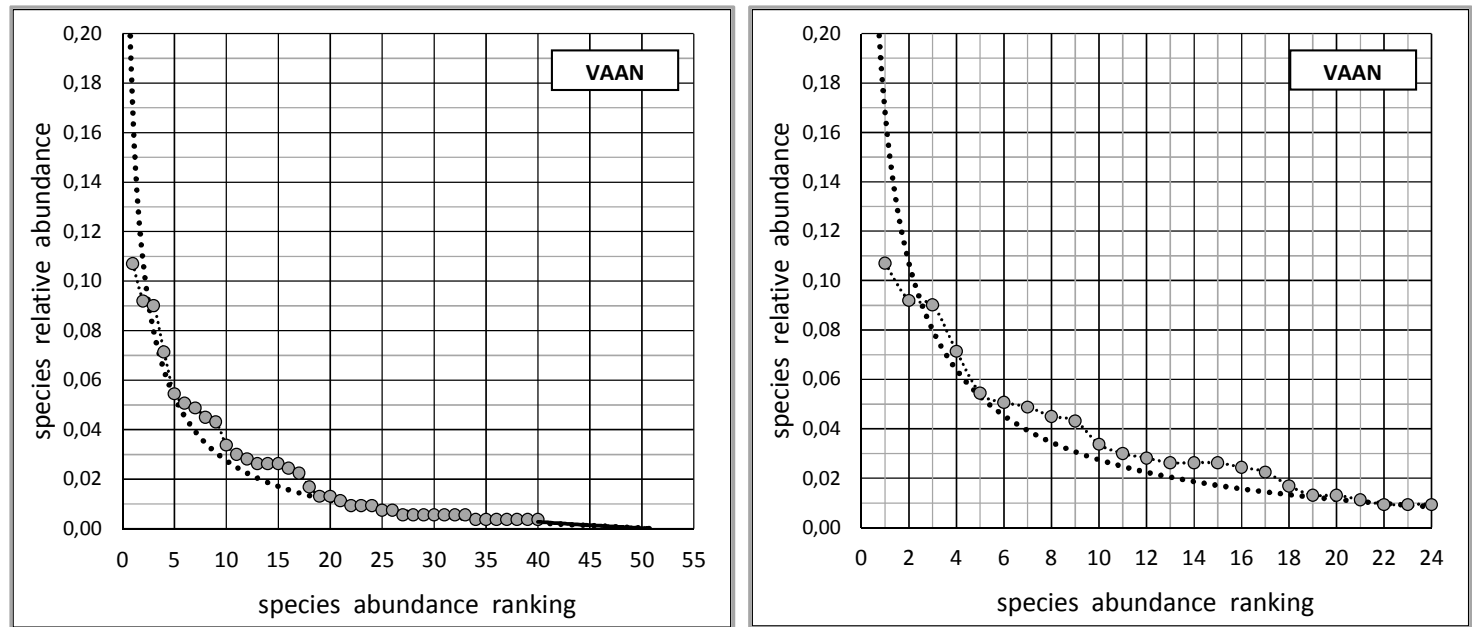

Fig. 10. Comparison between the bias-corrected and extrapolated "S.A.D." for the community at 'Vaan' island (grey circles and solid line) and the corresponding "log-normal" model (Dotted line)

Fig. 11. Same as Fig. 10 with arithmetical scale for abundances (instead of the traditional logarithmic scale), which offers a more direct visual appreciation of relative abundances, as suggested by MacArthur [29]

\subsection{The Genuine Intensity of the Process} of Hierarchical Structuration of Abundances

As emphasized in Methods section, the genuine intensity of the process driving the hierarchical structuration of abundances is relevantly appreciated by comparing the "S.A.D." of the studied community to the corresponding "brokenstick" model computed for the same species richness. Figs. 16 to 21 provide such comparisons of the "S.A.D." of each community with the corresponding "broken-stick" model, computed for the same species richness. 
In a more synthetic way, Table 3 will provide the evaluations of the genuine intensity, $\mathrm{I}_{\mathrm{str}}$, of the process driving the hierarchical structuration of species abundances, for each of the three communities.

\subsection{Species Richness and the Degree of Hierarchical Structuring of Species Abundances in Each Feeding Guild Considered Separately}

Two feeding guilds coexist in the three studied Gastropod communities: primary consumers ("herbivores") and secondary consumers ("carnivores"). The numerical extrapolation

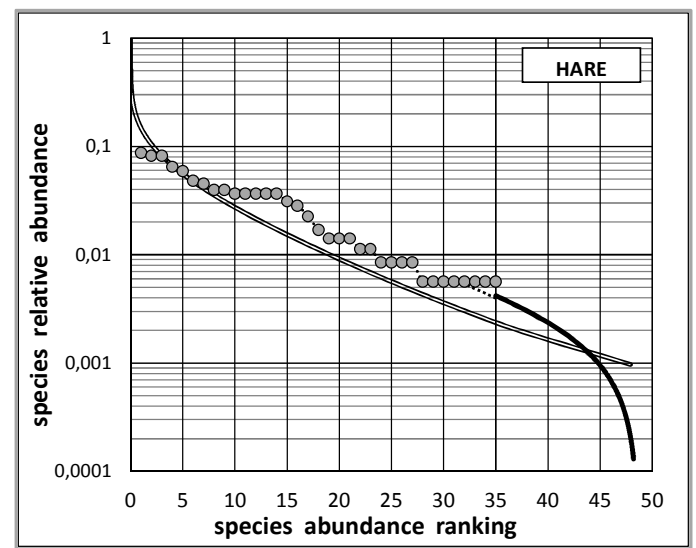

procedure, applied above to each community as a whole, may be implemented, as well, to each of these two feeding guilds, separately.

The respective contributions of each feeding guild - in terms of total species richness and cumulated number of individuals per guild - are derived accordingly (Table 2). In all three communities, the guild of secondary consumers is far more species-rich (by twice to almost thrice) than is the guild of primary consumers. Regarding the cumulated number of individuals per guild, the trend is less marked because primary consumers are more numerous by species, on average, than are secondary consumers.

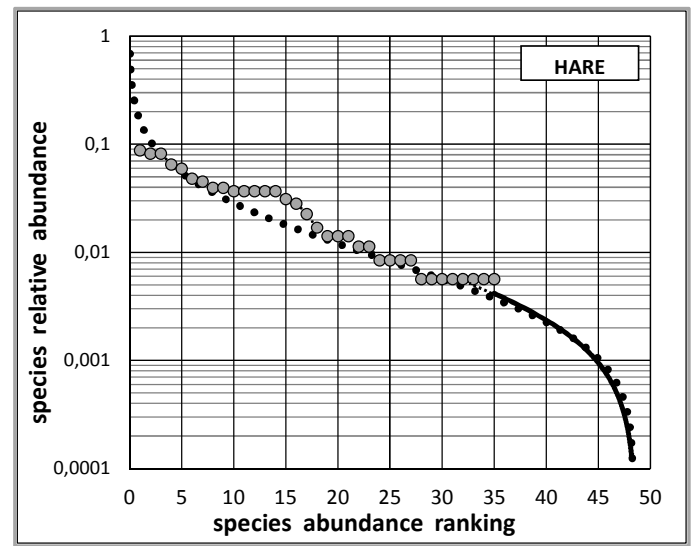

Fig. 12. Comparison between the bias-corrected and extrapolated "S.A.D." for the community at 'Hare' island (grey circles and solid line) and the corresponding "log-series" model (Double line)

Fig. 13. Comparison between the bias-corrected and extrapolated "S.A.D." for the community at 'Hare' island (grey circles and solid line) and the corresponding "log-normal" model (Dotted line)
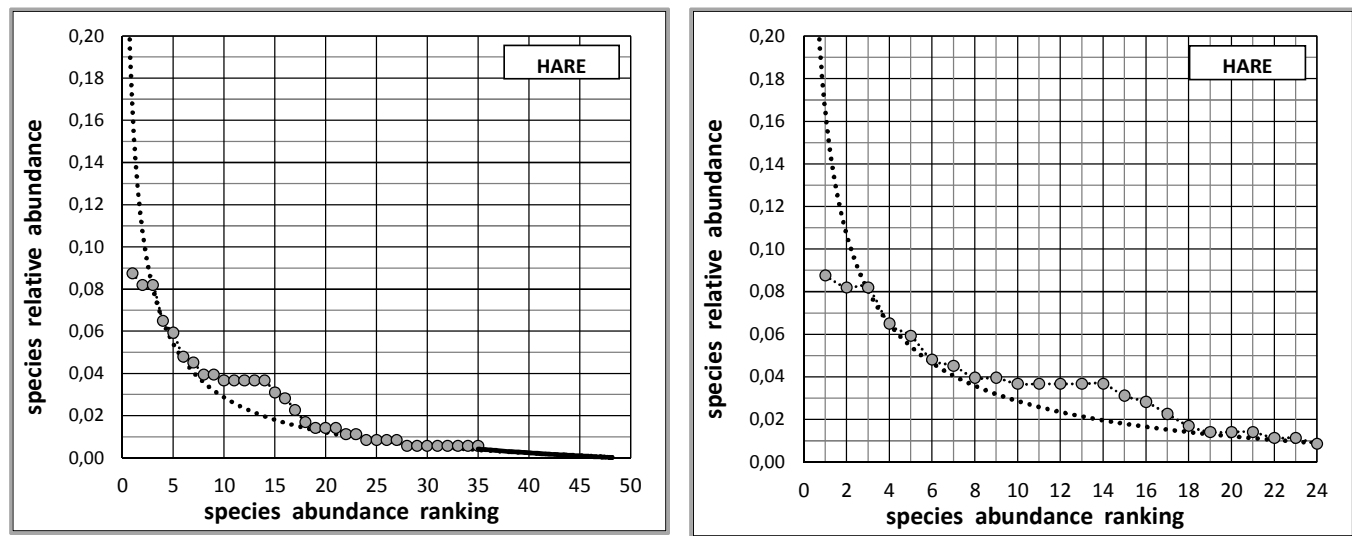

Fig. 14. Comparison between the bias-corrected and extrapolated "S.A.D." for the community at 'Hare' island (grey circles and solid line) and the corresponding "log-normal" model (Dotted line)

Fig. 15. Same as Fig. 14 with arithmetical scale for abundances (instead of the traditional logarithmic scale), which offers a more direct visual appreciation of relative abundances, as suggested by MacArthur [29] 

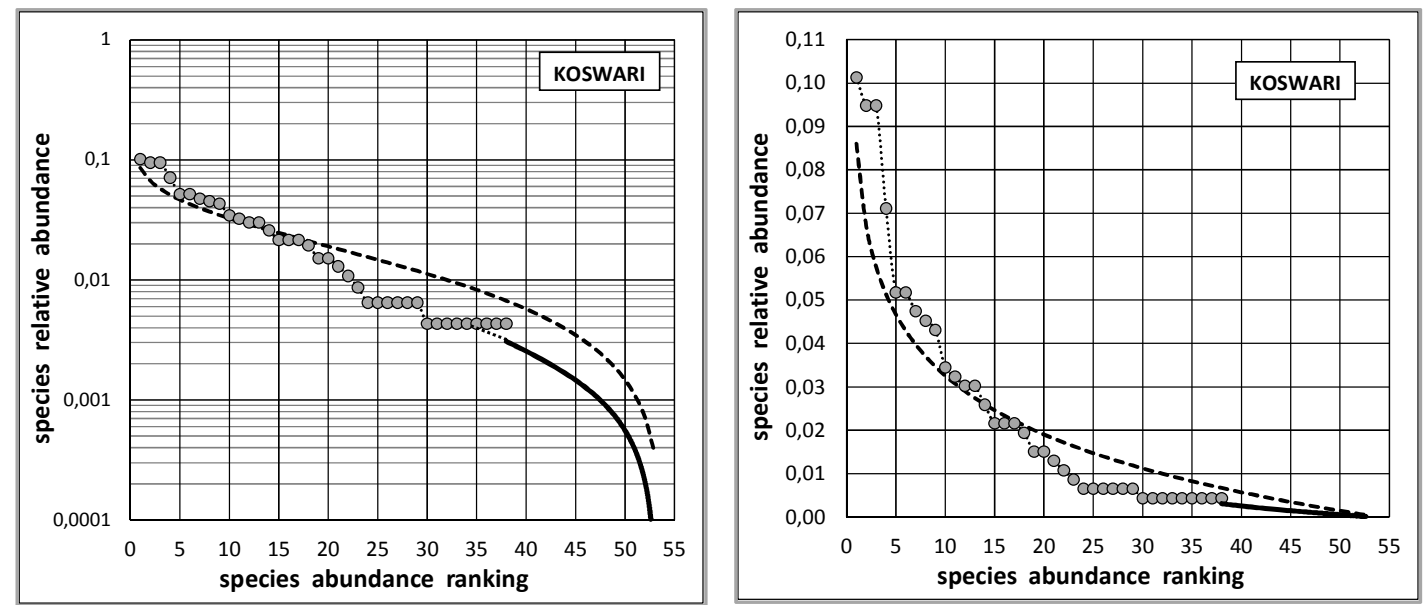

Fig. 16. Comparison between the bias-corrected and numerically extrapolated "S.A.D." for the community at 'Koswari' island (grey circles and solid line) and the corresponding "brokenstick" model (dashed line) - ordinate with logarithmic scale

Fig. 17. Comparison between the bias-corrected and numerically extrapolated "S.A.D." for the community at 'Koswari' island (grey circles and solid line) and the corresponding "brokenstick" model (dashed line) - ordinate with arithmetic scale
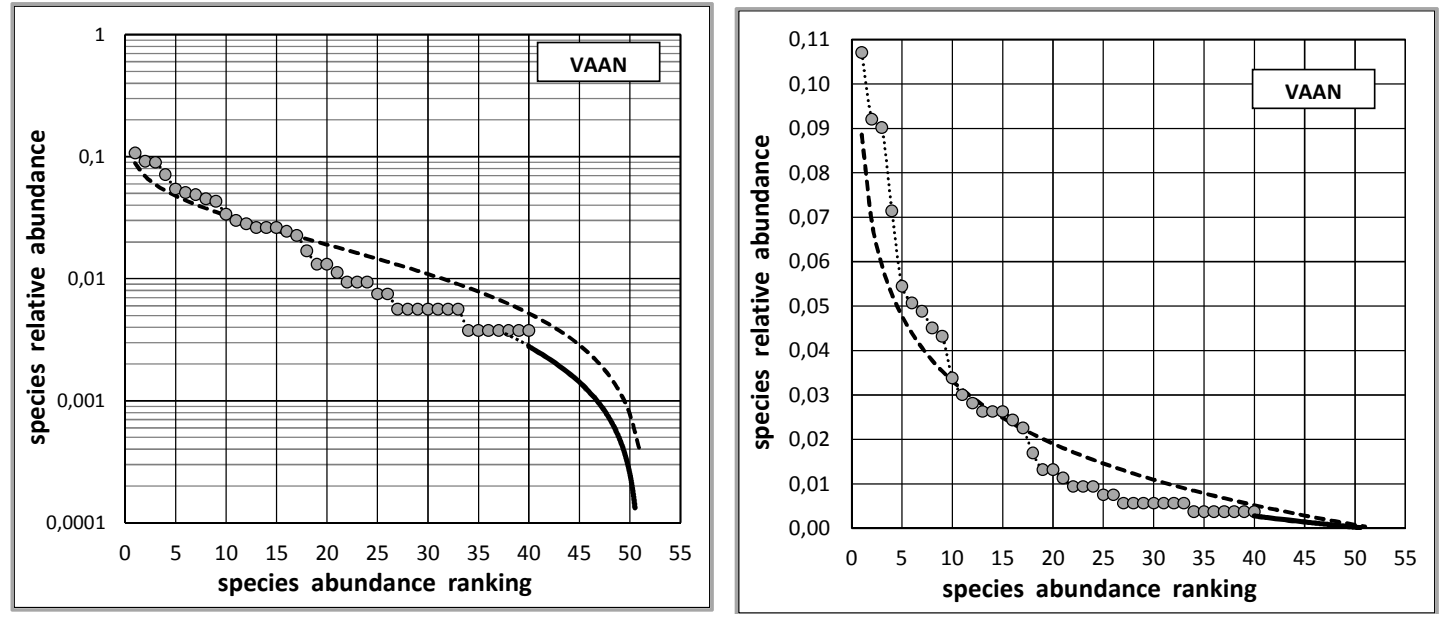

Fig. 18. Comparison between the bias-corrected and numerically extrapolated "S.A.D." for the community at 'Vaan' island (grey circles and solid line) and the corresponding "broken-stick" model (dashed line) - ordinate with a logarithmic scale

Fig. 19. Comparison between the bias-corrected and numerically extrapolated "S.A.D." for the community at 'Vaan' island (grey circles and solid line) and the corresponding "broken-stick" model (dashed line) - ordinate with arithmetic scale

Table 2. Respective contributions, per feeding guild (primary and secondary consumers), to:

(i) the recorded and total species richness and (ii) the cumulated numbers of individuals

\begin{tabular}{|c|c|c|c|c|c|c|}
\hline \multirow{3}{*}{$\begin{array}{l}\text { Respective contributions of } \\
\text { primary and secondary feeders }\end{array}$} & \multicolumn{6}{|c|}{ sites } \\
\hline & \multicolumn{2}{|c|}{ Hare } & \multicolumn{2}{|c|}{ Vaan } & \multicolumn{2}{|c|}{ Koswari } \\
\hline & Primar & Secund & Primar & Secund & Primar & Secund \\
\hline nb. recorded species $R_{0}$ & 6 & 29 & 7 & 33 & 6 & 32 \\
\hline nb. unrecorded species $\Delta$ & 2 & 12 & 1 & 10 & 4 & 11 \\
\hline total species richness $S_{t}$ & 8 & 41 & 8 & 43 & 10 & 43 \\
\hline contrib. to sp. richness $\%$ & $16 \%$ & $84 \%$ & $16 \%$ & $84 \%$ & $19 \%$ & $81 \%$ \\
\hline contrib. to nb. individ. \% & $28 \%$ & $72 \%$ & $32 \%$ & $68 \%$ & $31 \%$ & $69 \%$ \\
\hline
\end{tabular}



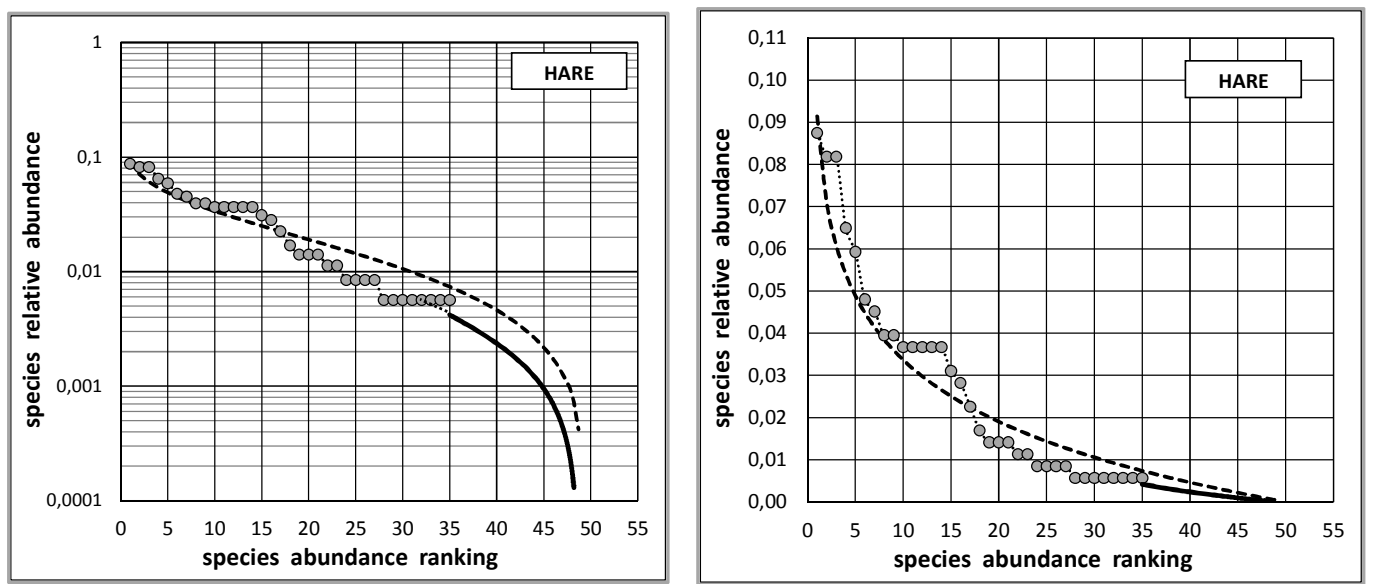

Fig. 20. Comparison between the bias-corrected and numerically extrapolated "S.A.D." for the community at 'Hare' island (grey circles and solid line) and the corresponding "broken-stick" model (dashed line) - ordinate with logarithmic scale

Fig. 21. Comparison between the bias-corrected and numerically extrapolated "S.A.D." for the community at 'Hare' island (grey circles and solid line) and the corresponding "ideally even" model (dotted line) and "broken-stick" model (dashed line) - ordinate with arithmetic scale

The Species Abundance Distributions specific to each of the two feeding guilds co-occurring in the community at 'Koswari' (the richest one, taken as an example) are jointly provided in Fig. 22.

These abundance distributions are drastically different, with a strongly steeper slope of the "S.A.D." for primary consumers than for secondary consumers. The distribution of species abundances among primary consumers appears, thus, far more uneven than it is among secondary consumers. This striking difference between the two feeding guilds still remains obvious when the slope of each species abundance distribution is compared to the slope of the corresponding "broken-stick" model (computed for the same species richness): Fig. 23. This means that not only the apparent unevenness (as a descriptive parameter), but also the intensity $I_{\text {str }}$ of the underlying process driving the hierarchical structuration of abundances (as a functional parameter) are stronger for primary consumers as compared to secondary consumers. $\mathrm{U}=0.272$ and $\mathrm{I}_{\text {str }}=1.79$ for primary consumers against $U=0.070$ and $I_{\text {str }}$ $=1.27$ only for secondary consumers

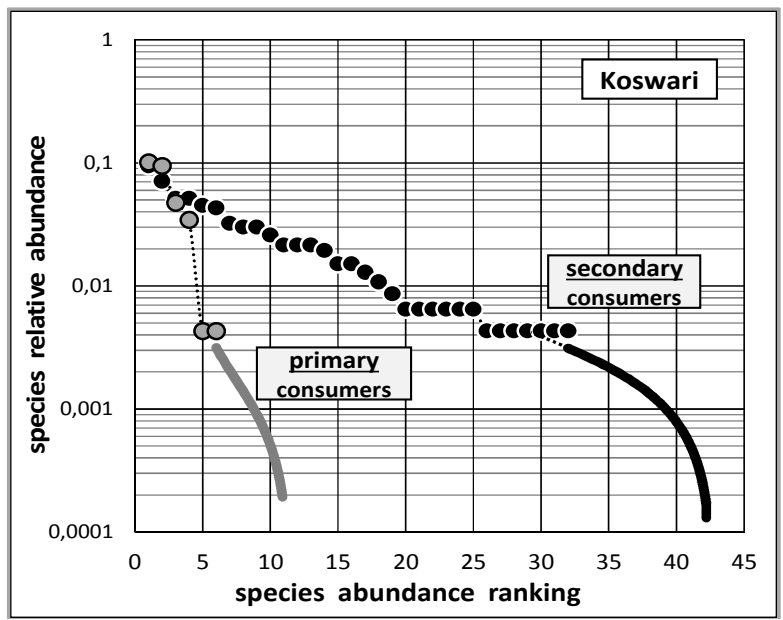

Fig. 22. The bias-corrected and extrapolated "S.A.D." for the two feeding guilds in the marine gastropod community at 'Koswari' island. Grey figures: The primary consumers; black figures: the secondary consumers. The distribution of species abundances among primary consumers is strikingly more uneven than it is among secondary consumers 


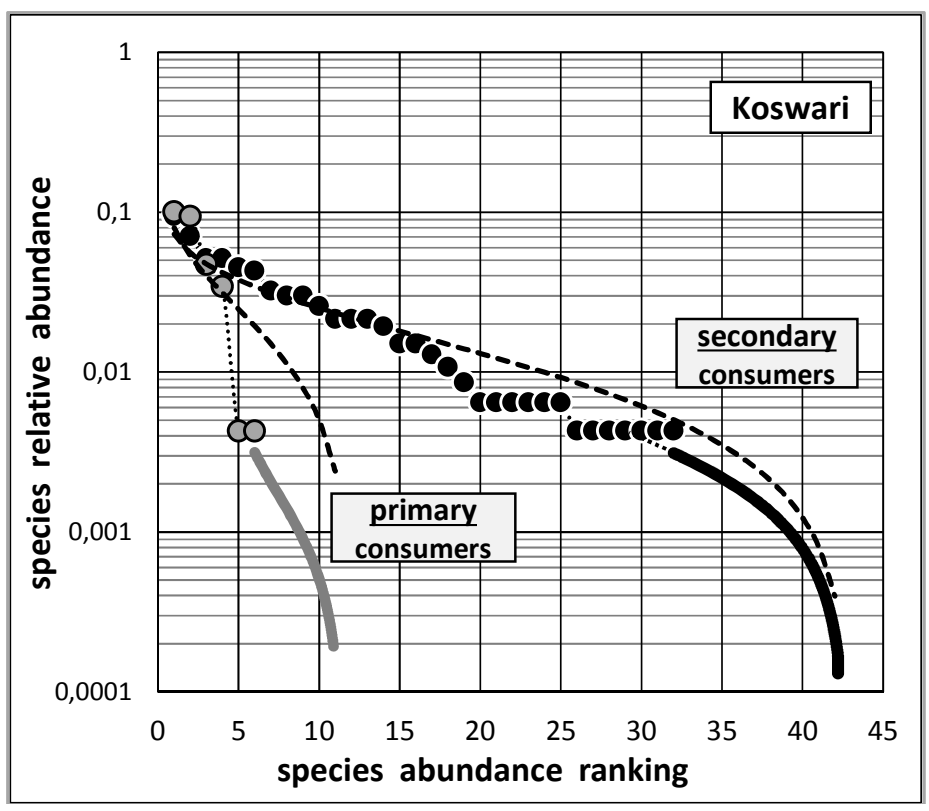

Fig. 23. Same as Fig. 22, with the additional superimposition of the corresponding "broken stick" models (dashed lines) for the primary consumers and for the secondary consumers respectively. The average slope of the "S.A.D." of secondary consumers is just slightly steeper than the corresponding "broken stick" model, while the average slope of the "S.A.D." of primary consumers is strongly steeper than the corresponding "broken stick" model

\subsection{Overview of the Main Quantitative Features Characterising the Three Communities}

The (extrapolated) total species richness on the one hand; the pattern $U$ and the intensity $I_{\text {str }}$ of the underlying process of hierarchical structuring of species abundances (exhaustively unveiled by numerical extrapolation) on the other hand, altogether convey much of the quantitative aspects that characterize the internal structuring of natural communities of species in their particular environment. The corresponding results for each of three communities are summarized in Table 3.
In turn, the main trends are highlighted in Fig. 24 in which both the abundance unevenness $U$ and the intensity of the structuring process $I_{\text {str }}$ are plotted together against the species richness $S_{t}$, for each three communities.

The (positive) dependence of the intensity $I_{\text {str }}$ of the structuring process upon species richness is functionally relevant, since $I_{\text {str }}$ was precisely defined freed from any direct (mathematical) dependence on $S_{t}$ a priori. Of course, three communities only do not suffice to draw any statistically sound conclusion and to propose any generalization, but the crude observation yet deserves being acknowledged.

Table 3. A synthetic summary of the main quantitative features of the structuration of species abundances within each community, as derived from the corresponding "S.A.D.", duly completed by extrapolation: (i) the total species richness $\mathrm{S}_{\mathrm{t}}$ of the community ; (ii) the relative abundances $a_{1}$ and $a_{S t}$ of the most and the least abundant species (ranks $i=1$ and $\left.i=S_{t}\right)$; (iii) the unevenness of abundances in the community: $U=\log \left(a_{1} / a_{s t}\right) /\left(S_{t}-1\right)$ and in the corresponding "broken-stick": $U$ ' $=\log \left(a_{1}{ }_{1} / a^{\prime}{ }_{s t}\right) /\left(S_{t}-1\right)$ and, at last, (iv) the genuine intensity of the structuring process $I_{\text {str }}=U / U^{\prime}$

\begin{tabular}{lccccccc}
\hline \multirow{2}{*}{ sites } & \multicolumn{7}{c}{ Parameters of the distribution of species abundances } \\
\cline { 2 - 8 } & $\mathbf{S}_{\mathbf{t}}$ & $\mathbf{a}_{\mathbf{1}}$ & $\mathbf{a}_{\mathbf{S t}}$ & $\mathbf{a}_{\mathbf{1}} / \mathbf{a}_{\mathbf{S t}}$ & $\mathbf{U}$ & $\mathbf{U}$ & $\mathbf{I}_{\text {str }}$ \\
\hline Koswari & 53 & 0.1012 & 0.000102 & 992 & 0.0577 & 0.0458 & 1.26 \\
Vaan & 51 & 0,1070 & 0.000132 & 811 & 0.0582 & 0.0473 & 1.23 \\
Hare & 49 & 0,0875 & 0.000130 & 673 & 0.0589 & 0.0487 & 1.21 \\
\hline
\end{tabular}


Now, and at first sight paradoxically, the level of unevenness $U$ is, on the contrary, decreasing with $S_{t}$. This, yet, is nothing else than the consequence of the mathematical, negative influence of the species richness on the apparent level of unevenness $U$, as already argued above. Thus, no functional relevance should be attributed to this decrease of U with St.

From a methodological point of view, this exemplifies the fact that sticking to the first appearance - that is, here, considering the level of unevenness as the likely faithful mirror of the strength of hierarchical ranking of species abundances - would lead to quite an erroneous appreciation. However, relying only on unevenness level still remains too often the usual practice!

\subsection{Three More Specific Comparisons}

Until now, all comparisons above failed to singularize any of the three communities from the other two.
However, the following, more specifically focused comparisons will best succeed in this respect.

\subsubsection{The pattern of abundance distribution according to feeding guild}

The "S.A.D." of each feeding guild (primary and secondary feeders) was surveyed as a whole in section 3.5. Yet, further insight may be obtained by considering how each feeding guild is represented among the half most abundant species (i.e. species with ranks $i<S_{t} / 2$ ) and among the half less abundant species (i.e. species with ranks $i \geq S_{t} / 2$ ). As shown in Table 4, fairly equal distributions (all rather close to $50 \%$ ) are recorded for both guilds in communities at 'Vaan' and at 'Koswari'. By contrast, at 'Hare', the primary consumer species are more than twice as frequent among the most abundant (ranks $\mathrm{i}<\mathrm{S}_{\mathrm{t}} / 2$ ) than among the least abundant (ranks $\mathrm{i} \geq \mathrm{S}_{t} / 2$ ): $69 \%$ against $31 \%$. The figure, however, still lacks statistical support, due to the small numbers of species involved.

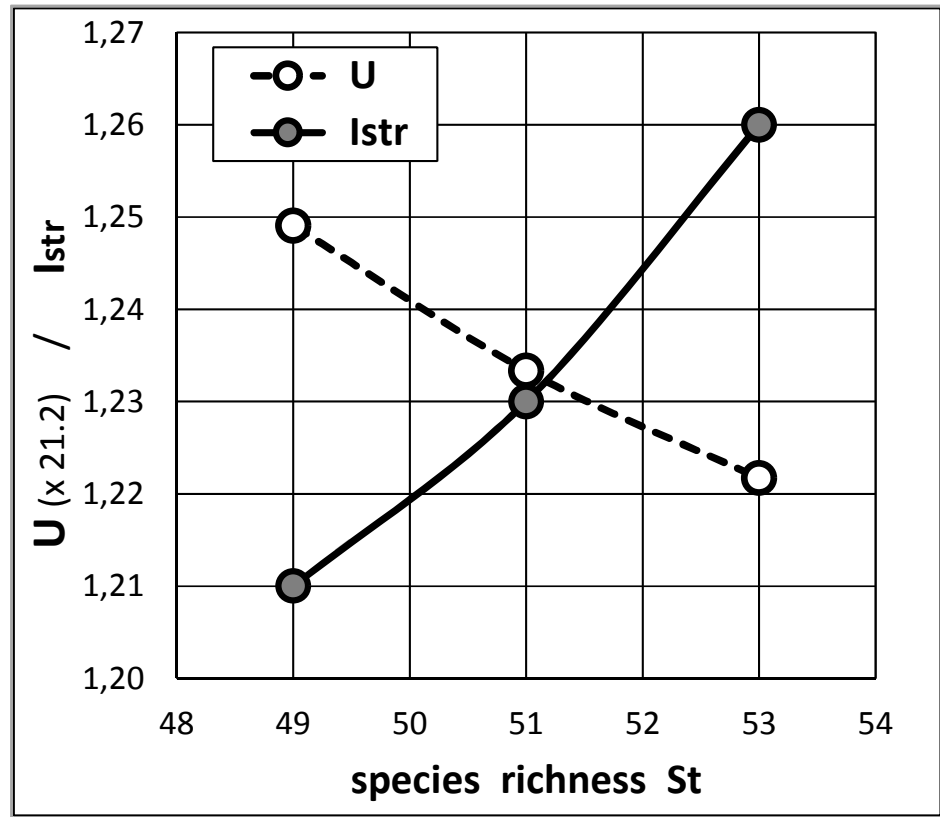

Fig. 24. The degree $U$ of apparent unevenness of species abundances (dashedline) and the genuine intensity $I_{s t r}$ of the underlying structuring process (solid line) plotted against the total species richness St, for the three studied marine Gastropod communities. The degree of unevenness decreases with increasing species richness of communities, while the opposite holds true for the genuine intensity of the structuring process driving this uneven distribution of species abundances: $I_{\text {str }}$ increases with increasing species richness of communities. The discrepancy results from the negative mathematical dependence of $U$ upon $S_{t}$. Note that for commodity of graphical comparison between $U$ and $I_{\text {str }}$ the degrees of unevenness are uniformly multiplied by a same factor 21.2 
Table 4. The numbers and proportions (\%) of species in each feeding guild that occur either (i) Among the half more abundant species, that is with rank $<S_{t} / 2$ or,

(ii) Among the half less abundant species, that is with rank $\geq S_{t} / 2$

\begin{tabular}{|c|c|c|c|c|c|c|}
\hline \multirow[t]{3}{*}{ Range of species abundances } & \multicolumn{6}{|c|}{ Sites } \\
\hline & \multicolumn{2}{|c|}{ Hare } & \multicolumn{2}{|c|}{ Vaan } & \multicolumn{2}{|c|}{ Koswari } \\
\hline & Primar & Secund & Primar & Secund & Primar & Secund \\
\hline half more abundant (rank $\left.<S_{t} / 2\right)$ & 5 & 19 & 4 & 21 & 5 & 21 \\
\hline half less abundant (rank $\left.\geq S_{t} / 2\right)$ & 2.2 & 22.5 & 4 & 22 & 5.6 & 21.5 \\
\hline half more abundant $\left(\operatorname{rank}<S_{t} / 2\right)$ & $69 \%$ & $45 \%$ & $50 \%$ & $49 \%$ & $47 \%$ & $49 \%$ \\
\hline half less abundant (rank $\geq S_{t} / 2$ ) & $31 \%$ & $55 \%$ & $50 \%$ & $51 \%$ & $53 \%$ & $51 \%$ \\
\hline
\end{tabular}

\subsubsection{The degree of hierarchical dominance of the three most abundant species}

The degree of hierarchical structuring of species abundances at each location was addressed at sections 3.4 and 3.6. Yet, further insight may be obtained by detailing the contribution to hierarchical dominance of the three most abundant species at each location (species of ranks $1,2,3)$. As already underlined, this contribution is best quantified after standardization to the corresponding "brokenstick" model. Accordingly, the ratio $\Sigma_{1 \mathrm{to} 3}\left[\mathrm{a}_{\mathrm{i}}\right] / \Sigma_{1 \mathrm{to} 3}$ [ $\left.a_{i}^{\prime}\right]$ is considered for each of three communities, with $a_{i}$ standing for the actual "S.A.D." and $a_{i}^{\prime}$ for the corresponding "broken-stick" distribution. The Bayesian inferences of the distribution of probabilities for the value of this ratio are provided at Fig. 25 for each location. The community at 'Hare' singularizes in this respect, as compared to the other two communities.

\subsubsection{The congruence of taxonomic identities within the set of most abundant species}

Beta-diversity, when comparing communities two by two, is a third, potentially distinctive criterion between communities at the three locations. To preserve significance, focus is placed on the set of the 16 most abundant species (Table 5).

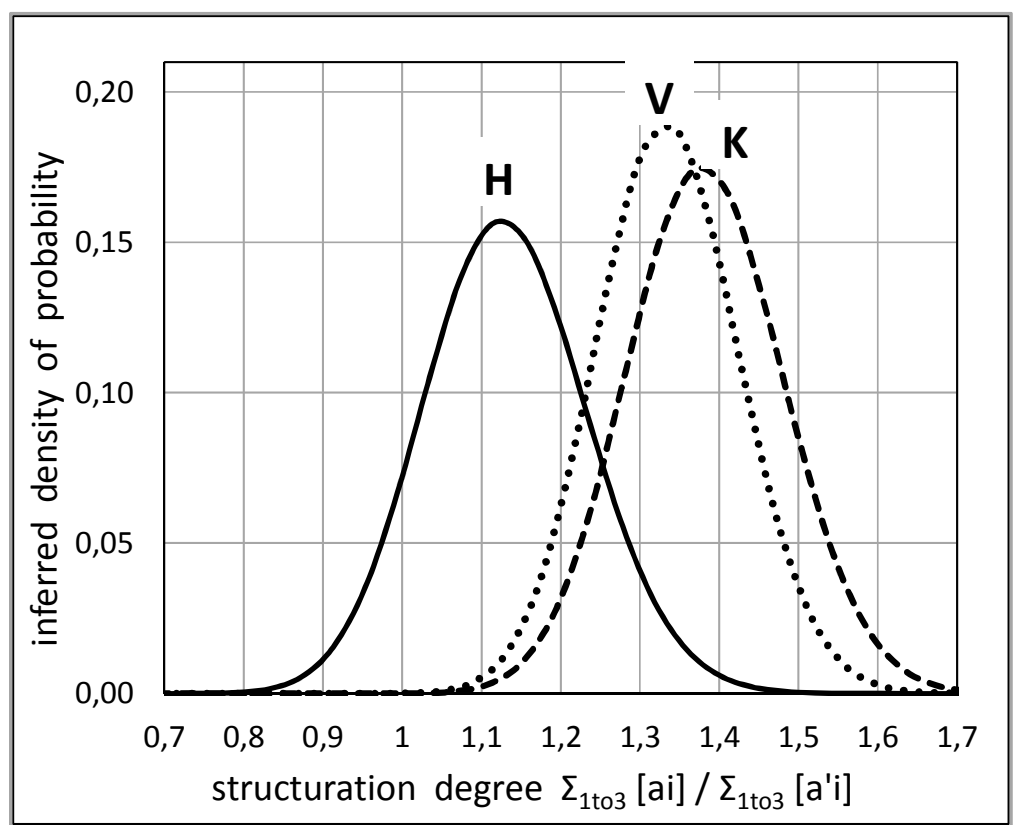

Fig. 25. Bayesian inferences applied to the degree of hierarchical dominance of the three most abundant species $\left(\Sigma a_{i}\right.$ for ranks $i=1$ to 3$)$ after standardization to the broken-stick model $\left(\Sigma a^{\prime}{ }_{i}\right.$ for ranks $i=1$ to 3 ). Thus defined, the degree of structuration is: $\Sigma_{1 \text { to3 }}\left[a_{i}\right] / \Sigma_{1 \text { to3 }}\left[a_{i}^{\prime}\right]$. Labels H, V, K are for Hare, Vaan, Koswari 
Table 5. Relative abundances $a_{i}$ of the 16 most abundant species in each of three locations 'Koswari' (K), 'Vaan' (V) and 'Hare' (H)

\begin{tabular}{|c|c|c|c|c|c|c|c|}
\hline \multirow[t]{2}{*}{ Species } & \multicolumn{3}{|c|}{ Sites } & \multirow[t]{2}{*}{ Species } & \multicolumn{3}{|c|}{ Sites } \\
\hline & $\mathbf{K}$ & $\mathbf{V}$ & $\mathbf{H}$ & & $\mathbf{K}$ & $\mathbf{V}$ & $\mathbf{H}$ \\
\hline Trochus niloticus Linné 1767 & 0,101 & 0,092 & 0,065 & Cypraea caurica (Linné 1758) & 0,043 & 0,043 & 0,037 \\
\hline Trochus radiatus Gmelin 1791 & 0,095 & 0,107 & 0,082 & Umbonium sp. & 0,034 & 0,034 & 0,037 \\
\hline Murex trapa Roding 1798 & 0,095 & 0,090 & 0,088 & Cypraea teres Gmelin 1791 & 0,032 & 0,026 & 0,048 \\
\hline Murex tribulus Linné 1758 & 0,071 & 0,071 & 0,082 & Cyparea labrolineata Gaskoin 1849 & 0,030 & 0,030 & 0,031 \\
\hline Hemifusus pugilinus (Born1778) & 0,052 & 0,051 & 0,059 & Chicoreus ramosus (Linné 1758) & 0,030 & 0,026 & 0,040 \\
\hline Cypraea moneta Linné 1758 & 0,052 & 0,049 & 0,037 & Vasum ceramicum (Linné 1758) & 0,006 & 0,008 & 0,045 \\
\hline Lambis lambis Linné 1758 & 0,047 & 0,054 & 0,037 & Nerita polita Linné 1758 & 0,000 & 0,004 & 0,037 \\
\hline Monetaria annulus (Linné 1758) & 0,045 & 0,045 & 0,040 & Cypraea miliaris Gmelin 1791 & 0,026 & 0,026 & 0,028 \\
\hline
\end{tabular}
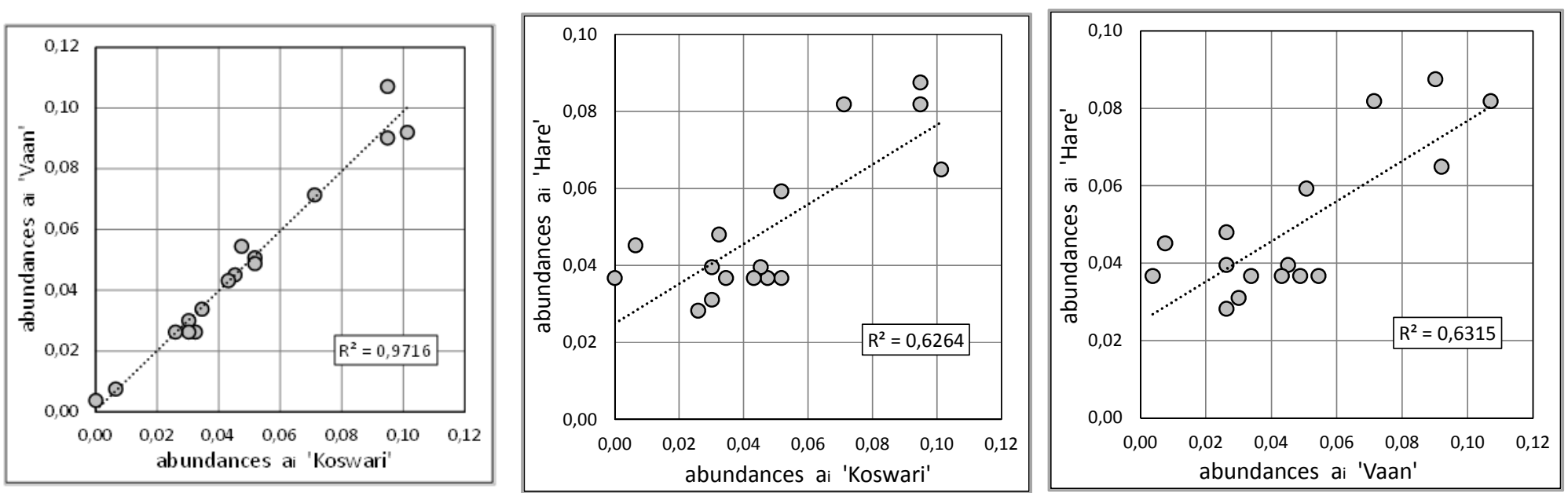

Figs. 26,27,28. Correlations between the relatives abundances $a_{i}$ for Koswari'-'Vaan', for 'Koswari'-'Hare' and for 'Vaan'-'Hare'. The sixteen most abundant species are considered 
The correlation between the relative abundances $a_{i}$ (ranks $i=1$ to 16 ) are plotted in Figs. 26, 27 , 28 for the three couples 'Koswari'-'Vaan', 'Koswari'-'Hare' and 'Vaan'-'Hare'. While a very strong correlation is observed between communities at 'Koswari' and 'Vaan' $\left(r^{2}=0.972\right)$, the correlations between the community at 'Hare' and the communities at either 'Koswari' or 'Vaan' are clearly weaker $\left(r^{2}=0.626\right.$ and $r^{2}=0.632$ respectively).

\section{DISCUSSION}

Coral reefs in shallow waters are among the most threatened ecosystems, as a consequence of anthropic activities, in particular the on-going climate change [1,2]. Assessing, at the local scale, the main quantitative descriptors of the animal communities associated to coral-reefs (in particular, the total species richness, the apparent level of unevenness of species abundances and the genuine intensity of the structuring process within communities) is thus a first urgency. Yet, the urgency on the one hand and the completeness of assessments on the other hand often are contradictory requirements, difficult to conciliate in practice. Hence, the usual constraint of having to cope with substantially incomplete samplings and, accordingly, to apply least-biased numerical extrapolations to these partial samplings. Implementing such a procedure allows, in turn, to infer all necessary quantitative information relative to the set of unrecorded species: (i) estimating their number and (ii) inferring their abundance distribution. Thereby, total species richness and the full-range of the Species Abundance Distribution ("S.A.D."), including the undetected species, may both be derived, thus providing essential information that, otherwise, would have remain out of reach. The procedures to carry out these extrapolations, with minimum bias, have been recently made available $[18,33,34]$, so that now, nothing prevents from making the most of "rapid samplings" or "quick assessments".

\subsection{Common Features to All Three Gastropod Communities}

\subsubsection{Each community considered as a whole} (Independently of feeding guilds)

\subsubsection{Total species richness and abundance distribution}

The three studied gastropod communities, associated to coral reefs surrounding the small islands of 'Koswari', 'Vaan' and 'Hare' show similar total species richness $(53,51$ and 49 species respectively, Table 1) and also share rather similar "S.A.D.s" features (Figs. 1, 2, 3). This, indeed, was expected from the similarity of environments between these three locations [15].

Moreover, the expected additional sampling effort that would be required to progressively unveil the taxonomical identities of the still unrecorded species is provided by the numerically extrapolated Species Accumulation Curve of each community, as already reported in [16].

The average total species richness $(\approx$ fifty species) found for these local communities of marine shelled-Gastropods may be put in the regional context of the same fauna for Mannar Gulf considered as a whole. The figures for marine Gastropods in Mannar Gulf are comprised between 260 species [35] and 450 species [15]. That is, between $\approx 240$ and $\approx 410$ shelled-species, after setting aside the nonshelled species (which are less than 10\%, according to Wägle and Klussmann-Kolb [36]). Thus, the proportion of this regional richness actually present at the local scale of the studied coral reefs is likely comprised between 50/410 and $50 / 240$, i.e. between $12 \%$ and $21 \%$ of the regional stock. This is rather in line with the range of values reported in Witman et al. [37] for the ratios of species richness between the local and the corresponding regional scale, in tropical benthic ecosystems.

\subsubsection{Inferred origin of the hierarchical structuration of species abundances}

For all three communities, the abundance distributions ("S.A.D.S") reveal clearly more consistent with the "log-normal" model than with the "log-series" model (Figs. 4-5, 8-9, 12-13). This, in fact, seems to be a rather frequent trend, likely being common to most wild communities of species approaching or having reached some kind of dynamic equilibrium $[22,24,25]$. Note that the affiliation to "log-normal" rather than to "logseries" models would have been less obvious if only non-extrapolated "S.A.D.s" were available (see Figs. 4, 8, 12). This is in line with the opinion according to which incomplete distributions, lacking the set of rarest (unrecorded) species may often lead erroneously - to a better fitting to the "log-series" model [24]. Thus, relevantly addressing the kind of process driving the hierarchical structuration of 
species abundances in communities imperatively requires (here also and once again) considering the full range of "S.A.D.s" and, thus, implementing numerical extrapolation as far as necessary.

This consistency of all three "S.A.D.s" with the "log-normal" model suggests a process of hierarchical structuration of species abundances involving the combined contributions of many independent factors, rather than the sole contribution only one (or very few) dominant factor [10,22-25].

Now, a more detailed examination (see Figs. 6-7, 10-11, 14-15) shows, however, that in all three communities, the most abundant species (species of rank $\mathrm{i}=1$ and, to a much lesser extent, of rank $i=2$ ) departs significantly from the "log-normal" model, with an abundance $a_{1}$ of the most abundant species being only $\approx$ half the expected value according to the "log-normal" model for $i=1$. This gap between observation and expectation - statistically highly significant $(p$ $<0.001$ ) - may result from a variety of possible causes [38, see also 22]:

- From a "saturation" effect: while, according strictly to the "log-normal" model, the most abundant species would be intended to profit by the freely cumulative contributions of all positively influencing factors, this cumulative process may, yet, tend to saturate by itself;

- From the degree of "maturation" of communities still not being sufficiently close to their potential dynamic equilibrium thus preventing the most competitive species from having yet reached their asymptotic level of abundance [38];

- From some positively density-dependent detrimental factor, becoming predominant when species relative abundance approaches 0.10 ; this detrimental factor may, in turn, result either:

- From intra-specific competition for resource, [39] or

- From inter-specific interactions, such as predation (which, often, is positively dependent on prey density).

Whatever may be the nature of the cause involved, the latter is likely being non-taxon specific since the identity of the most abundant species differs in each of the three studied community: Trochus niloticus at 'Koswari', Trochus radiatus at 'Vaan', Murex trapa at 'Hare'.
At last, it should be noted, by contrast, that such a (punctual) departure from the "log-normal" model is not reported for the intertidal gastropod fauna along rocky shore at Middle Andaman Island, which strictly follows the "log-normal" model, even at the level of the most abundant species [19].

\subsubsection{The intensity of the hierarchical structuration of species abundances}

The hierarchical structuration of species abundances - in short, graphically, the slope of the "S.A.D." - may be considered two ways: (i) either purely descriptively as a pattern or (ii) more deeply analysed, by considering the underlying process driving the differential allocations of abundances among co-occurring species. Figs. 1 to 3 and Figs. 16 to 21 respectively address these two focus, eventually summarized in Table 3. As regards the pattern, the average steepness of the "S.A.D." slope (directly readable from Figs. 1 to 3 and quantified by unevenness level $U\left(=\log \left(a_{1} / a_{S t}\right) /\left(S_{t}-1\right)\right.$, in Table 3 ) is relatively similar in all three communities. Accordingly, the apparent degree of unevenness of species abundances is not distinctive among the three communities.

Yet, as argued in Methods section, the degree of unevenness of species abundances in a community does not reliably reflect the intensity of the hierarchical structuring of species abundances, because unevenness is also mathematically sensitive to the total species richness of the community.

However, a relevant appreciation of the intensity of the hierarchical structuring process, freed from the (spurious) influence of species richness, was obtained:

- Graphically, by plotting simultaneously the Species Abundance Distribution under study and the corresponding "broken-stick" model, computed for the same level of species richness (Figs. 16 to 21),

- Quantitatively, by standardizing the average slope of the Species Abundance Distribution under study to the average slope of the corresponding "broken-stick" model, thus leading to the definition (equation (1)) of the genuine intensity $I_{\text {str }}$ of the process driving the hierarchical structuring of species abundances (Table 3). Thereby leaving aside the purely mathematical influence of species richness 
on unevenness, the index $\mathrm{I}_{\text {str }}$ reliably reflects the specifically biological contribution made to the apparent level of unevenness.

Thereby, this mathematical independence between $\mathrm{I}_{\text {str }}$ and species richness confers a true biological significance to any empirical correlation that would happen to be recognized between $\mathrm{I}_{\text {str }}$ and total species richness. Hence, the interest of plotting $I_{\text {str }}$ against $S_{t}$, as proposed in Fig. 24. In addition, this representation has the advantage of providing a synthetic overview of the main results derived from this new kind of methodological approach.

The intensity $I_{\text {str }}$ of the structuring process slightly differs according to communities, ranging from 1.21 to 1.26 , (Table 3 ). Interestingly, here, $I_{\text {str }}$ increases with the total species richness $S_{t}$ of communities. And, as just mentioned, this empirically assessed dependence between $\mathrm{I}_{\text {str }}$ and $S_{t}$ should be considered as biologically relevant. This, indeed, is an original and important finding, contrasting with the previously reported results obtained for a series of tropical frog communities in N-W Ghats, where, on the contrary, $I_{\text {str }}$ consistently remains independent from $S_{t}[30]$.

\subsubsection{Feeding quilds considered separately in each community}

Feeding guilds constitute major functional subunits within species communities. As such, they deserve separate consideration, as regards both their own species richness and their own distribution of species abundances. In the studied gastropod communities, two feeding guilds are co-occurring: primary consumers ("herbivores") and secondary consumers ("carnivores"). The "S.A.D.s" specific to each feeding guild were therefore assessed separately and the corresponding numerical extrapolation were implemented for each specific "S.A.D." as well: Fig. 22.

\subsubsection{Contrasted contributions of primary and secondary consumers to species richness and to the numbers of individuals}

The respective contributions of primary and secondary consumers regarding the number of species and the number of individuals are given in Table 2. Relatively similar figures were obtained for the three studied communities, with a markedly reduced contribution of primary consumers ("herbivores") as compared to secondary consumers ("carnivores"), for both the species richness and the cumulated numbers of individuals. Primary consumers contribute to an overall $15 \%-20 \%$ of species richness and $28 \%$ $32 \%$ of the cumulated number of individuals, for each of the three communities. Accordingly, in these communities associated to coral reefs, secondary consumers make the bulk of the gastropod fauna in terms of both species richness and number of individuals. Interestingly, this is in relative contrast with the corresponding figures obtained with the intertidal gastropod fauna sampled along rocky shore at Middle Andaman Island [19], where primary consumers, contribute for no less than $39 \%$ of total species richness, thus approaching the contribution of secondary consumers. The contrast is still stronger, regarding the cumulated number of individuals among primary consumers, which reaches $60 \%$ at Andaman rocky shore and, thus, exceeds the figure for secondary consumers. This should arguably be related to the difference in algal cover between coral reefs and rocky shores. As a rule, algal cover is significantly lower on healthy coral reefs [40-43] than on degraded reefs [1] or rocky shores [44]. Thus, healthy coral reefs - such as those studied here - are expected to be less appealing to primary consumers than are the degraded coral reefs or the rocky shores, all of them supporting higher algal covers. A similar conclusion was drawn from the observation of healthy coral reefs along Kenyan coast, where most reef-associated Gastropods turn out to be secondary consumers: the proportion of predatory gastropods is comprised between $70 \%$ and $99 \%$ (average $86 \%)$, depending on reefs types and location [45].

\subsubsection{Contrasted degree of hierarchical structuration of species abundances between primary and secondary consumers}

Both the apparent unevenness $U$ of species abundances (the average slopes of "S.A.D.s" at Fig. 22) and the genuine intensity $I_{\text {str }}$ of the underlying structuring process (the slopes of "S.A.D.s" compared with those of the "brokenstick" distribution at Fig. 23) are markedly stronger for primary consumers than for secondary consumers: $U=0.300$ and $I_{\text {str }}=1.92$ for primary consumers, against $\mathrm{U}=0.068$ and $\mathrm{I}_{\text {str }}$ $=1.27$ only for secondary consumers. The still more striking gap regarding apparent 
unevenness $U$ (a 4.4 times higher unevenness for primary consumers) results, as expected, from the additional influence on unevenness of the smaller species richness of primary consumers.

Interestingly, the same tendency is highlighted for the intertidal gastropod fauna of rocky shore in Andaman Islands [19] and for the gastropod fauna associated to coral-reefs in Fiji Islands [31]. In fact, the trend for higher unevenness in the guild of primary consumers might well be general for most marine and terrestrial ecosystems, as argued on both theoretical and empirical basis in [46].

Moreover, the much stronger value of the intensity $I_{s t r}$ of the structuring process for primary consumers suggests that the trend for higher unevenness of abundances among primary consumers does not result only from the influence of their reduced species richness. In fact, there is also a significant contribution of some purely biological cause(s) to the much stronger unevenness of species abundances within the guild of primary consumers. Indeed, this was a question which was still remaining unanswered after the publication of reference [46], as the author does not consider the genuine intensity of the structuring process, nor even the apparent evenness pattern, but the "Hill number", which, in fact, combines apparent evenness and species richness and thus quantifies the diversity rather than evenness itself. The present results thus shed significant new light on this issue.

\subsection{Minor Features Singling Out the Community at 'Hare' as Compared to 'Koswari' and 'Vaan'}

Until now, the three gastropods communities were hardly found differing from each other, which is not surprising, considering their very similar environmental conditions. Yet, addressing a series of more subtle factors allows to slightly singularize the community at 'Hare' from the other two communities, at 'Koswari' and 'Vaan'.

First, as shown in Table 4, the species belonging to the guild of primary consumers appear fairly equally distributed all along the range of species abundances, as regards the communities at 'Vaan' and 'Koswari'. By contrast, at 'Hare', the primary consumer species are more than twice more frequent in the upper half than in the lower half of the range of species abundances.
Second, as shown in Fig. 25, the degree of hierarchical dominance of the three most abundant species differs according to sites; with a slightly, but yet significantly, lower dominance value at 'Hare' as compared to both 'Vaan' and 'Koswari'.

Third, as shown in Figs. 26 to 28 , there is a trend for higher congruence in the relative abundances, considered species by species, when comparing 'Vaan' and 'Koswari' than when comparing 'Hare' to either 'Vaan' or 'Koswari'.

Thus, for each of the three criteria above, it is always the community at 'Hare' which singularizes from the other two communities, located at 'Vaan' and 'Koswari'. This is suggestive, as 'Vaan' and 'Koswari' are only a few kilometers apart while 'Hare' is distant from about 150 kilometers from the other two localities. The results above thus anecdotally highlight the effective, although limited extent to which distance may contribute to slightly affect the features of communities which, on the other hand, are placed in y very similar environments and profit by the same regional stock of species. A point, however, discussed in more details by Diamond [47].

Besides, it is worth noting that Mohanraj and coworkers [15], although relying only on the partial samplings of the gastropod assemblages of each three islands, had already concluded also for a slightly greater taxonomical proximity between the assemblages of "Vaan" and "Koswari", as compared to "Hare". A pattern that they had already hypothesized as the consequence of the closer spatial proximity of "Vaan" and "Koswari", as compared to "Hare".

\subsection{Numerical Extrapolation: A Useful Complement to Partial Species Inventories}

Considering in details the data implicitly conveyed by Species Abundance Distributions can provide an astonishing diversity of information relative to the internal structuration of species communities, which, in turn, can have both theoretical and practical interest. However, taking such full advantage from the treatment of Species Abundance Distributions requires dealing with the exhaustive range of the distributions of abundances, which in practice is rarely possible, especially when having to cope with species-rich communities, as are, for example, most invertebrate assemblages. Hence the necessity of implementing a reliable 
procedure of numerical extrapolation to extend the still incomplete Species Abundance Distributions [48], as was proceeded here.

This is all the more important that rare species, that, obviously, more frequently escape recording in practice, may yet disproportionately contribute to the functional structuring of communities in the wild [49]. Accordingly, numerical extrapolation remains the only way to account for their existence and role. Moreover - as frustrating as it may seem - the lack of taxonomic identification of these rare species (remaining undetected in the field but highlighted by numerical extrapolation) has more limited consequences that could have been thought at first. Indeed, the specific taxonomic identification turns out to be of less importance, as soon as one is aware of the generally great variability of taxonomic compositions that can equally well answer a same type of functionality [50].

\subsection{Final Consideration Regarding the Methodological Approach to the Internal Organization within Species Communities}

For a local assemblage of species to be relevantly regarded - and fruitfully understood as a community of species, it is necessary to go beyond the purely descriptive pattern of community organization, trying to address the meaningful underlying process driving this organization [38]. In other words, it is necessary to go beyond the empirical level of unevenness (as the apparent pattern of community organization), deliberately aiming at characterizing the genuine intensity of the underlying structuring process driving the differential allocation of relative abundances among co-occurring species. This distinction between the immediately apparent pattern and the deeper underlying process makes, here, specific sense. Moreover, this distinction even has essential implications, because it happens that the pattern of the as-observed unevenness cannot faithfully mirror the intensity of the structuring process itself, since the level of unevenness is also influenced, purely mathematically $[26,27]$, by the species richness of the community. An important point indeed, already argued previously [12,13,26-28] but, yet, still remaining ignored too frequently in common practice. This systematic - and biologically irrelevant - influence, should thus be set aside if the true biological meaning of abundance unevenness is to be relevantly understood.
The ("biologically spurious") mathematical influence of species richness on abundance unevenness may be evidenced quantitatively by considering how unevenness would vary with species richness while the nature of the structuring process is constrained to remain unchanged. The "broken-stick" distribution [29] provides such an opportunity, as it involves an unchanged process of random allocation of relative abundances among species, whatever species richness can be. So that, the "brokenstick" distribution is uniquely dependent upon (and solely parametrized by) the species richness only [10]. The "broken-stick" distribution may thus serve as a relevant "null model" against which to compare empirical Species Abundance Distributions.

This has been fully taken into account, here, as a major methodological improvement aiming at a better understanding of the drivers of the internal structuring within species communities.

\section{CONCLUSION}

After being numerically completed, using a recently developed least-biased extrapolation procedure, the Species Abundance Distributions of the three reef-associated gastropod communities reveal remarkably similar to each other, although no specific connection exists between these three communities, one of them being even located $150 \mathrm{~km}$ apart from the other two. In particular, the Species Abundance Distributions of the three communities all comply fairly well with the log-normal model, suggesting that, in each case, the process of hierarchical structuration of species abundances likely involves the combined contributions of many mutually independent factors. The same trend to similarity holds true for all other major characteristic of each of the three Species Abundance Distributions.

Only a fine, in-depth analysis proves able to highlight some subtle distinctions between the three communities and, interestingly, precisely for the site (Hare), located $150 \mathrm{~km}$ apart from the two others.

In addition to the information specific to the studied Gastropod communities associated to coral-reefs in Mannar Gulf, some new results, of more general interest, were highlighted, in particular regarding the two co-occurring feeding guilds. 
Thus, as compared to secondary consumers ("carnivores"), the guild of primary consumers ("herbivores") is clearly distinguished by a comparatively lower species richness and a strongly higher degree of abundance unevenness (as already emphasized recently. But, moreover, the genuine intensity of the process of hierarchical structuring of species abundance itself was also demonstrated as being markedly stronger within the guild of primary consumers. To my knowledge, this last point is reported here for the first time.

Given the growing threat posed by global warming to the integrity of coral reefs $[1,2,51]$, it features essential to multiply detailed and exhaustive inventories - such as those conducted here with the support of numerical extrapolation - in order to accumulate sufficient contemporary data to serve as reference for subsequent monitoring of the future evolution of coral reefs ecosystems.

\section{ACKNOWLEDGEMENTS}

Three anonymous reviewers are gratefully acknowledged for their comments and appreciations on the original manuscript

\section{COMPETING INTERESTS}

Author has declared that no competing interests exist.

\section{REFERENCES}

1. Graham NAJ, Wilson SK, Jennings S, Polunin NVC, Bijoux JP, Robinson J. Dynamic fragility of oceanic coral reef ecosystems. Proceedings of the National Academy of Sciences USA. 2006;103(22): 8425-8429.

2. Ziegler $M$, Quéré $G$, Ghiglione JF, Iwankow G, Barbe V, Boissin E, Wincker $P$, Planes S, Voolstra CR. Status of coral reefs of Upolu (Independent State of Samoa) in the South West Pacific and recommendations to promote resilience and recovery of coastal ecosystems. Marine Pollution Bulletin. 2018;129:392398.

3. Wells JW. Coral reefs: 609-632; in J.W. Hedspeth editor, Treatise on marine eclogy and paleoecology. Geological Society of America. 1957;67.

4. Glynn PW. High complexity food webs in low-diversity eastern Pacific reef-coral communities. Ecosystems. 2004;7:358367.
5. Jeeva C, Mohan PM, Sabith DB, Ubare VV, Muruganantham M, Kumari RK. Distribution of gastropods in the intertidal environment of south, middle and north Andaman Islands, India. Open Journal of Marine Science. 2018;8:173-195.

6. Connolly SR, Hughes TP, Bellwood DR. A unified model explains commonness and rarity on coral reefs. Ecology Letters. 2017; 20:477-486.

7. Cam E, Nichols JD, Sauer JR, Hines JE. On the estimation of species richness based on the accumulation of previously unrecorded species. Ecography. 2002;25: 102-108.

8. Rajakaruna $\mathrm{H}$, Drake DAR, Chan FT, Bailey SA. Optimizing performance of nonparametric species richness estimators under constrained sampling. Ecology and Evolution. 2016;6:7311-7322.

9. Chen Y, Shen TJ. Rarefaction and extrapolation of species richness using an area-based Fisher's logseries. Ecology and Evolution. 2017;7:10066-10078.

10. May RM. Patterns of species abundance and diversity. In Cody ML, Diamond JM. Ecology and Evolution of Communities. The Belknap Press of Harvard University. 1975;81-120.

11. McGill BJ, Etienne RS, Gray JS, et al. Species abundance distributions: Moving beyond single prediction theories to integration within an ecological framework. Ecology Letters. 2007;10:995-1015.

12. Ulrich $\mathrm{W}$, Ollik $\mathrm{M}$, Ugland $\mathrm{KI}$. A metaanalysis of species-abundance distributions. Oikos. 2010;119:1149-1155.

13. Komonen A, Elo M. Ecological response hides behind the species abundance distribution: Community response to lowintensity disturbance in managed grasslands. Ecology and Evolution. 2017;7: 8558-8566.

14. Wang X, Ellwood F, AI D, Zhang R, Wang G. Species abundance distributions as a proxy for the niche-neutrality continuum. Journal of Plant Ecology. 2017;13.

15. Mohanraj J, Johnson JA, Ranjan R, Johnson L, Pandi U, Shunmugaraj T. Coral reef associated gastropods in Tuticorin coast of Gulf of Mannar Biosphere Reserve, India. Indian Journal of Science and Technology. 2010;3(2):204-206.

16. Béguinot J. Extrapolation of total species richness from incomplete inventories: Application to the Gastropod fauna associated to coral reefs in 'Mannar Gulf 
Biosphere Reserve', India. Asian Journal of Environment and Ecology. 2017;4(3):114.

DOI: 109734/AJEE/2017/36831

17. Chao A, Hsieh T, Chazdon RL, Colwell RK, Gotelli NJ. Unveiling the species-rank abundance distribution by generalizing the Good-Turing sample coverage theory. Ecology. 2015;96(5):1189-1201.

18. Béguinot J. How to extrapolate species abundance distributions with minimum bias when dealing with incomplete species inventories. Advances in Research. 2018; 13(4):1-24.

DOI: $10.9734 / A I R / 2018 / 39002$

19. Béguinot J. Numerical extrapolation of the species abundance distribution unveils the true species richness and the hierarchical structuring of a partially sampled marine gastropod community in the Andaman Islands (India). Asian Journal of Environment and Ecology. 2018;6(4):1-23.

DOI: 10.9734/AJEE/2018/41293

20. Heip CHR, Herman PMJ, Soetaert K. Indices of diversity and evenness. Océanis. 1998;24(4):61-87.

21. Grzès IM. Ant species richness and evenness increase along a metal pollution gradient in the Boleslaw zinc smelter area. Pedobiologia. 2009;53:65-73.

22. Loreau M. Species abundance patterns and the structure of ground-beetle communities. Ann. Zool. Fennici. 1992;28: 49-56.

23. Magurran AE, Henderson PA. Explaining the excess of rare species in natural species abundance distributions. Nature. 2003;422:714-716.

24. Connolly SR, Hughes TP, Bellwood DR, Karlson RH. Community structure of corals and reef fishes at multiple scales. Science. 2005;309:1363-1365.

25. Ulrich W, Soliveres S, Thomas AD, Dougill AJ, Maestre FT. Environmental correlates of species rank-abundance distributions in global drylands. Europe PMC Funders Group. 2016;20:56-64.

26. Smith B, Wilson JB. A consumer's guide to evenness indices. Oikos. 1996;76:70-82.

27. Loiseau N, Gaertner JC. Indices for assessing coral reef fish biodiversity: The need for a change in habits. Ecology and Evolution. 2015;5(18):4018-4027.

28. MacDonald ZG, Nielsen SE, Acorn JH. Negative relationships between species richness and evenness render common diversity indices inadequate for assessing long-term trends in butterfly diversity. Biodiversity Conservation. 2017;26:617629.

29. MacArthur RH. On the relative abundance of bird species. Proceedings of the National Academy of Sciences U.S.A. 1957;43:293-295.

30. Béguinot J. Estimating true species richness and the degree of hierarchical structuring of species abundances in eight frog communities from the north-western Ghats of India. International Journal of Environment and Climate Change. 2018; 8(2):118-137.

DOI: $10.9734 / / J E C C / 2018 / 42067$

31. Béguinot J. Analyzing the role of environmental stresses on both species richness and the hierarchical structuring of species abundances in marine Gastropods communities at Suva (Fiji Islands). in preparation; 2011.

32. Mohanraj J, Chelladurai G, Balakrishnan S, Kuamr IV. Gulf of Mannar island coral reef associated gastropods assemblage: Distribution and diversity pattern. Journal of Coastal life Medicine. 2015;3(9):691695.

33. Béguinot J. Theoretical derivation of a bias-reduced expression for the extrapolation of the Species Accumulation Curve and the associated estimation of total species richness. Advances in Research. 2016;7(3):1-16.

DOI: $10.9734 / \mathrm{AIR} / 2016 / 26387$

34. Béguinot J. Extrapolation of the species accumulation curve associated to "Chao" estimator of the number of unrecorded species: A mathematically consistent derivation. Annual Research \& Review in Biology. 2016;11(4):1-19.

DOI: 10.9734/ARRB/2016/30522

35. Mohanraj $\mathrm{T}$, Jagadis $\mathrm{I}$, Sivanesh $\mathrm{H}$. Association of molluscan fauna with the coral reefs of Gulf of Mannar. European Journal of Experimental Biology. 2011; 1(3):44-48.

36. Wägle $\mathrm{H}$, Klussmann-Kolb $\mathrm{A}$. Opisthobranchia (Mollusca, Gastropoda) more than just slimy slugs. Shell reduction and its implications on defense and foraging. Frontiers in Zoology. 2005;2(3). DOI: 10.1186/1742-9994-2-3

37. Witman JD, Etter RJ, Smith F. The relationship between regional and local species diversity in marine benthic communities: A global perspective. Proceedings of the National Academy of 
Sciences USA. 2004;101(44):1566415669.

38. Connell JH. Some mechanisms producing structure in natural communities: A model and evidence from field experiments. In Cody ML, Diamond JM. Ecology and evolution of communities. The Belknap Press of Harvard University. 1975;460490.

39. Skilleter GA, Underwood AJ. Intra- and inter-specific competition for food in infaunal coral reef gastropods. Journal of Experimental Marine Biology and Ecology. 1993;173(1):29-55.

40. Villanueva RD, Edwards AJ, Bell JD. Enhancement of grazing Gastropod populations as a coral reef restoration tool: Predator effects and related applied implications. Restoration Ecology. 2010; 18(6):803-809.

41. Rasher DB, Hoey AS, Hay ME. Consumer diversity interacts with prey defenses to drive ecosystem function. Ecology. 2013; 94(6):1347-1358.

42. Mailloux NA. Increasing coral cover and decreasing coral species diversity with decreasing light availability ta depth: a study of the future effects of sea level rise on fringing reef ecosystems. Physis. 2014; 16:48-54

43. Rempel $\mathrm{H}$. Control of algae on coral reefs by large herbivorous fishes. Physis. 2014; 16:55-65.

44. Martinez E, Sanchez J, Alba A, Vazquez AA. Changes in structure and composition of two communities of rocky shores molluscs exposed to different human impact in Playa Jibacoa. Journal of Ecosystem and Ecography. 2015;5(2):1-6.

45. McClanahan TR. Kenyan coral reefassociated gastropod fauna: A comparison between protected and unprotected reefs. Marine Ecology Progress Series. 1989;53: 11-20.

46. Garcia-Callejas D. On the variability of species abundance distributions with trophic guild and community structure. Bio Rxiv; 2018.

DOI: $10.1101 / 289348$

47. Diamond JM. Assembly of species communities. In Cody ML, Diamond JM. Ecology and evolution of communities. The Belknap Press of Harvard University. 1975; 81-120.

48. Kery M, Royle JA. Inference about species richness and community structure using species-specific occupancy models in the
National Swiss Breeding Bird survey MUB. Proceedings of the 2007 EURING Technical Meeting and Workshop, Dunedin, New Zealand; 2007.

49. Leitao RP, Zuanon J, Villéger S, Williams SE, Baraloto C, Fortunel C, Mendonça FP, Mouillot D. Rare species contribute disproportionately to the functional structure of species assemblages. Proceedings of The Royal Society B. 2016;283:0084.

DOI: 10.1098/rspb.2016.0084

50. Louca S, Jacques SMS, Pires APF, Leal JS, Srivastava DL, Wegener Parfrey L, Farjalla VF, Doebeli M. High taxonomic variability despite stable functional structure across microbial communities. Nature Ecology and Evolution. 2016;1: 0015.

DOI: 10.1038/s41559-016-0015

51. Bellwood DR, Hughes TP, Folke C, Nyström M. Confronting the coral crisis. Nature. 2004;429:827-830.

52. Béguinot J. An algebraic derivation of Chao's estimator of the number of species in a community highlights the condition allowing Chao to deliver centered estimates. ISRN Ecology; 2014.

(Article ID 847328)

DOI: $10.1155 / 2014 / 847328$

53. Béguinot J. When reasonably stop sampling? How to estimate the gain in newly recorded species according to the degree of supplementary sampling effort. Annual Research \& Review in Biology. 2015;7(5):300-308.

DOI : 10.9734/ARRB/2015/18809

54. O'Hara RB. Species richness estimators: How many species can dance on the head of a pin? Journal of Animal Ecology. 2005; 74:375-386.

55. Gotelli NJ, Colwell RK. Estimating species richnessin: Biological Diversity: Frontiers in Measurement and Assessment. Magurran AE, McGill BJ. (eds.). Oxford University Press, Oxford. 2010;345,39-54.

56. Gotelli NJ, Chao A. Measuring and estimating species richness, species diversity, and biotic similarity from sampling data. In: Levin SA. (ed.) Encyclopedia of Biodiversity. Waltham, MA: Academic Press. 2013;5:195-211.

57. Brose U, Martinez ND, Williams RJ. Estimating species richness: Sensitivity to sample coverage and insensitivity to spatial patterns. Ecology. 2003;84(9): 2364-2377. 


\section{Appendix 1}

\section{Correction and extrapolation (when required) of the as-recorded S.A.D.}

N.B.: details regarding the derivation of the following expressions are provided in [18].

1) Correction for bias of the recorded part of the S.A.D.

The bias-corrected expression of the true abundance, $\tilde{a}_{\mathrm{i}}$, of species of rank ' $\mathrm{i}$ ' in the S.A.D. is:

$$
\tilde{a}_{i}=p_{i} \cdot\left(1+1 / n_{i}\right) /\left(1+R_{0} / N_{0}\right) \cdot\left(1-f_{1} / N_{0}\right)
$$

where $N_{0}$ is the actually achieved sample size, $R_{0}\left(=R\left(N_{0}\right)\right)$ the number of recorded species, among which a number $f_{1}$ are singletons (species recorded only once), $n_{i}$ is the number of recorded individuals of species ' $i$ ', so that $p_{i}=n_{i} / N_{0}$ is the recorded frequency of occurrence of species ' $i$ ', in the sample. The crude recorded part of the "S.A.D." - expressed in terms of the series of as-recorded frequencies $p_{i}=n_{i} / N_{0}$ - should then be replaced by the corresponding series of expected true abundances, $\tilde{a}_{\mathrm{i}}$, according to equation (A1.1).

2) Extrapolation of the recorded part of the S.A.D. accounting for the complementary abundance distribution of the set of unrecorded species

The following expression stands for the estimated abundance, $a_{i}$, of the unrecorded species of rank $i$ (thus for $\mathrm{i}>\mathrm{R}_{0}$ ):

$$
a_{i}=\left(2 / N_{i}\right) /\left(1+R\left(N_{i}\right) / N_{i}\right) \cdot\left(1-[\partial R(N) / \partial N]_{N_{i}}\right)
$$

which, in practice, comes down to: $a_{i} \approx\left(2 / N_{i}\right) /\left(1+R\left(N_{i}\right) / N_{i}\right)$, as $f_{1}(N)$ already becomes quite negligible as compared to $\mathrm{N}$ for the extrapolated part.

This equation provides the extrapolated distribution of the species abundances $a_{i}$ (for $i>R\left(N_{0}\right)$ ) as a function of the least-biased expression for the extrapolation of the species accumulation curve $R(N)$ (for $N>N_{0}$ ), 'i' being equal to $R\left(N_{i}\right)$. The key to select the least-biased expression of $R(N)$ is provided at Appendix 2. 


\section{Appendix 2}

\section{Bias-reduced extrapolation of the Species Accumulation Curve and associated bias-reduced estimation of the number of missing species, based on the recorded numbers of species occurring 1 to 5 times}

Consider the survey of an assemblage of species of size $\mathrm{N}_{0}$ (with sampling effort $\mathrm{N}_{0}$ typically identified either to the number of recorded individuals or to the number of sampled sites, according to the inventory being in terms of either species abundances or species incidences), including $R\left(N_{0}\right)$ species among which $f_{1}, f_{2}, f_{3}, f_{4}, f_{5}$, of them are recorded $1,2,3,4,5$ times respectively. The following procedure, designed to select the less-biased solution, results from a general mathematical relationship that constrains the theoretical expression of any theoretical Species Accumulation Curves $R(N)[33,52,53]$ :

$$
\partial^{x} R_{(N)} / \partial N^{x}=(-1)^{(x-1)} f_{x(N)} / C_{N, x} \approx(-1)^{(x-1)}\left(x ! / N^{x}\right) f_{x(N)} \quad(\approx \text { as } N>>x)
$$

Compliance with the mathematical constraint (equation (A.1)) warrants reduced-bias expression for the extrapolation of the Species Accumulation Curves $R(N)$ (i.e. for $N>N_{0}$ ). Below are provided, accordingly, the polynomial solutions $R_{\mathbf{x}}(\mathrm{N})$ that respectively satisfy the mathematical constraint (A2.1), considering increasing orders $x$ of derivation $\partial^{x} R_{(N)} / \partial N^{x}$. Each solution $R_{x}(N)$ is appropriate for a given range of values of $f_{1}$ compared to the other numbers $f_{x}$ [33]:

$$
\begin{aligned}
& { }^{*} \text { for } \mathrm{f}_{1} \text { up to } \mathrm{f}_{2} \rightarrow \mathrm{R}_{1}(\mathrm{~N})=\left(\mathrm{R}\left(\mathrm{N}_{0}\right)+\mathrm{f}_{1}\right)-\mathrm{f}_{1} \cdot \mathrm{N}_{0} / \mathrm{N} \\
& \text { * for larger } \mathrm{f}_{1} \text { up to } 2 \mathrm{f}_{2}-\mathrm{f}_{3} \rightarrow \mathrm{R}_{2}(\mathrm{~N})=\left(\mathrm{R}\left(\mathrm{N}_{0}\right)+2 \mathrm{f}_{1}-\mathrm{f}_{2}\right)-\left(3 \mathrm{f}_{1}-2 \mathrm{f}_{2}\right) \cdot \mathrm{N}_{0} / \mathrm{N}- \\
& \left(f_{2}-f_{1}\right) \cdot N_{0}^{2} / N^{2} \\
& \text { * for larger } f_{1} \text { up to } 3 f_{2}-3 f_{3}+f_{4} \rightarrow R_{3}(N)=\left(R\left(N_{0}\right)+3 f_{1}-3 f_{2}+f_{3}\right)-\left(6 f_{1}-8 f_{2}+3 f_{3}\right) \cdot N_{0} / N- \\
& \left(-4 f_{1}+7 f_{2}-3 f_{3}\right) \cdot N_{0}^{2} / N^{2}-\left(f_{1}-2 f_{2}+f_{3}\right) \cdot N_{0}^{3} / N^{3} \\
& \text { * for larger } \mathrm{f}_{1} \text { up to } 4 \mathrm{f}_{2}-6 \mathrm{f}_{3}+4 \mathrm{f}_{4}-\mathrm{f}_{5} \rightarrow \mathrm{R}_{4}(\mathrm{~N})=\left(\mathrm{R}\left(\mathrm{N}_{0}\right)+4 \mathrm{f}_{1}-6 \mathrm{f}_{2}+4 \mathrm{f}_{3}-\mathrm{f}_{4}\right)- \\
& \left(10 f_{1}-20 f_{2}+15 f_{3}-4 f_{4}\right) \cdot N_{0} / N-\left(-10 f_{1}+25 f_{2}-21 f_{3}+6 f_{4}\right) \cdot N_{0}^{2} / N^{2}- \\
& \left(5 f_{1}-14 f_{2}+13 f_{3}-4 f_{4}\right) \cdot N_{0}{ }^{3} / N^{3}-\left(-f_{1}+3 f_{2}-3 f_{3}+f_{4}\right) \cdot N_{0}{ }^{4} / N^{4} \\
& \text { * for } f_{1} \text { larger than } 4 f_{2}-6 f_{3}+4 f_{4}-f_{5} \rightarrow R_{5}(N)=\left(R\left(N_{0}\right)+5 f_{1}-10 f_{2}+10 f_{3}-5 f_{4}+f_{5}\right) \\
& -\left(15 f_{1}-40 f_{2}+45 f_{3}-24 f_{4}+5 f_{5}\right) \cdot N_{0} / N-\left(-20 f_{1}+65 f_{2}-81 f_{3}+46 f_{4}-10 f_{5}\right) \cdot N_{0}^{2} / N^{2}- \\
& \left(15 f_{1}-54 f_{2}+73 f_{3}-44 f_{4}+10 f_{5}\right) \cdot N_{0}^{3} / N^{3}-\left(-6 f_{1}+23 f_{2}-33 f_{3}+21 f_{4}-5 f_{5}\right) \cdot N_{0}{ }^{4} / N^{4}- \\
& \left(f_{1}-4 f_{2}+6 f_{3}-4 f_{4}+f_{5}\right) \cdot N_{0}^{5} / N^{5}
\end{aligned}
$$

The associated non-parametric estimators of the number $\Delta_{\jmath}$ of missing species in the sample [with $\Delta_{\lrcorner}$ $=R(N=\infty)-R\left(N_{0}\right)$ ] are derived immediately:

$$
\begin{aligned}
& { }^{*} \mathrm{f}_{1} \leq \mathrm{f}_{2} \rightarrow \Delta_{\mathrm{J} 1}=\mathrm{f}_{1} ; \mathrm{R}_{1}(\mathrm{~N}) \\
& { }^{*} \mathrm{f}_{2}<\mathrm{f}_{1} \leq 2 \mathrm{f}_{2}-\mathrm{f}_{3} \rightarrow \Delta_{\mathrm{J} 2}=2 \mathrm{f}_{1}-\mathrm{f}_{2} ; \mathrm{R}_{2}(\mathrm{~N}) \\
& { }^{*} 2 \mathrm{f}_{2}-\mathrm{f}_{3}<\mathrm{f}_{1} \leq 3 \mathrm{f}_{2}-3 \mathrm{f}_{3}+\mathrm{f}_{4} \rightarrow \Delta_{J 3}=3 \mathrm{f}_{1}-3 \mathrm{f}_{2}+\mathrm{f}_{3} ; \mathrm{R}_{3}(\mathrm{~N}) \\
& { }^{*} 3 \mathrm{f}_{2}-3 \mathrm{f}_{3}+\mathrm{f}_{4}<\mathrm{f}_{1} \leq 4 \mathrm{f}_{2}-6 \mathrm{f}_{3}+4 \mathrm{f}_{4}-\mathrm{f}_{5} \rightarrow \Delta_{J 4}=4 \mathrm{f}_{1}-6 \mathrm{f}_{2}+4 \mathrm{f}_{3}-\mathrm{f}_{4} ; \quad \mathrm{R}_{4}(\mathrm{~N}) \\
& { }^{*} \mathrm{f}_{1}>4 \mathrm{f}_{2}-6 \mathrm{f}_{3}+4 \mathrm{f}_{4}-\mathrm{f}_{5} \rightarrow \Delta_{J 5}=5 \mathrm{f}_{1}-10 \mathrm{f}_{2}+10 \mathrm{f}_{3}-5 \mathrm{f}_{4}+\mathrm{f}_{5} ; \quad \mathrm{R}_{5}(\mathrm{~N})
\end{aligned}
$$

N.B. 1: As indicated above (and demonstrated in details in [33], this series of inequalities define the ranges that are best appropriate, respectively, to the use of each of the five estimators, JK-1 to JK-5. That is the respective ranges within which each estimator will benefit of minimal bias for the predicted number of missing species. 
Besides, it is easy to verify that another consequence of these preferred ranges is that the selected estimator will always provide the highest estimate, as compared to the other estimators. Interestingly, this mathematical consequence, of general relevance, is in line with the already admitted opinion that all non-parametric estimators provide under-estimates of the true number of missing species $[8,9,54-$ 56]. Also, this shows that the approach initially proposed in [57] - which has regrettably suffered from its somewhat difficult implementation in practice - might be advantageously reconsidered, now, in light of the very simple selection key above, of far much easier practical use.

N.B. 2: In order to reduce the influence of drawing stochasticity on the values of the $f_{x}$, the asrecorded distribution of the $f_{x}$ should preferably be smoothened: this may be obtained either by rarefaction processing or by regression of the as-recorded distribution of the $f_{x}$ versus $x$.

N.B. 3: For $f_{1}$ falling beneath $0.6 \times f_{2}$ (that is when sampling completeness closely approaches exhaustivity), then Chao estimator may alternatively be selected: see reference [33]. 


\section{Appendix 3}

The trivial ("mechanistic") contribution of the level of species richness to the degree of structuring of species abundances

All things equal otherwise, the larger the species richness, the weaker is the slope of the Species Abundance Distribution.

This can be easily exemplified and quantified, on a theoretical basis, by considering a theoretically constant structuring process - such as the random distribution of the relative abundances that characterizes the "broken-stick" distribution model. By applying this model successively to a series of communities with increasing species richness, a steadily decrease of the slope of abundance distributions is highlighted: Fig. A3.

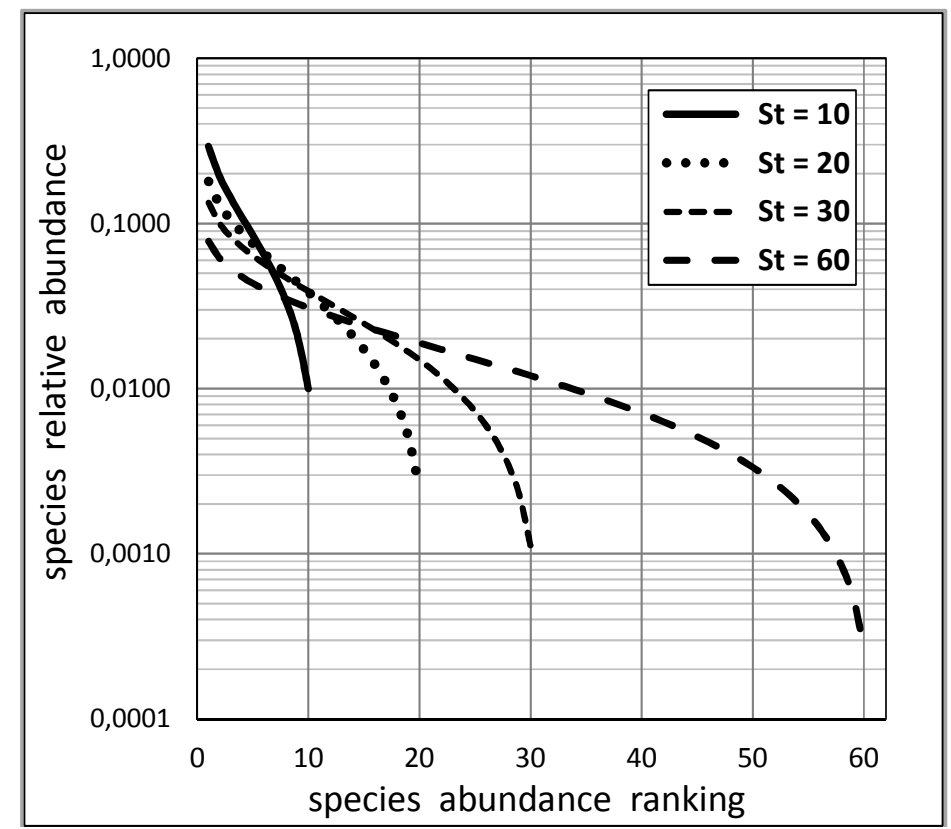

Fig. A3. The "broken-stick" distribution model applied to species communities with increasing species richness $S_{t}=10,20,30,60$. Although the theoretical structuring process involved in the "broken-stick" model remains unchanged (random apportionment of relative abundances among member species), the slope of the species abundance distribution strongly depends upon (and monotonously decreases with) the level of species richness $S_{t}$

(0) 2018 Béguinot; This is an Open Access article distributed under the terms of the Creative Commons Attribution License (http://creativecommons.org/licenses/by/4.0), which permits unrestricted use, distribution, and reproduction in any medium, provided the original work is properly cited.

Peer-review history:

The peer review history for this paper can be accessed here: http://www.sciencedomain.org/review-history/26313 